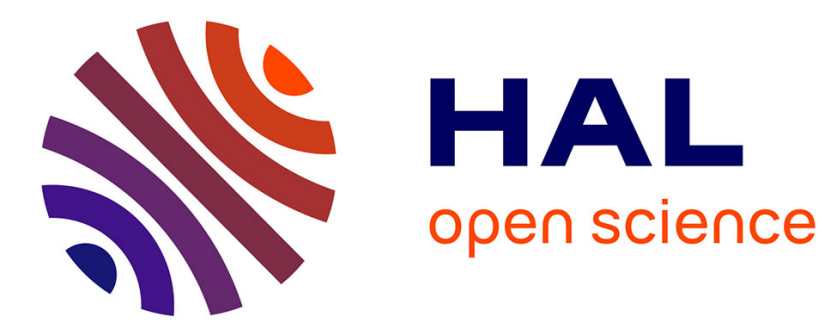

\title{
Simulations of an aircraft with constant and pulsed blowing flow control at the engine/wing junction
}

David Hue, Christophe François, Julien Dandois, Anna Gebhardt

\section{To cite this version:}

David Hue, Christophe François, Julien Dandois, Anna Gebhardt. Simulations of an aircraft with constant and pulsed blowing flow control at the engine/wing junction. Aerospace Science and Technology, 2017, 69, pp.659-673. 10.1016/j.ast.2017.07.031 . hal-01721678

\section{HAL Id: hal-01721678 \\ https://hal.science/hal-01721678}

Submitted on 2 Mar 2018

HAL is a multi-disciplinary open access archive for the deposit and dissemination of scientific research documents, whether they are published or not. The documents may come from teaching and research institutions in France or abroad, or from public or private research centers.
L'archive ouverte pluridisciplinaire HAL, est destinée au dépôt et à la diffusion de documents scientifiques de niveau recherche, publiés ou non, émanant des établissements d'enseignement et de recherche français ou étrangers, des laboratoires publics ou privés. 


\title{
Simulations of an Aircraft with Constant and Pulsed Blowing Flow Control at the Engine/Wing Junction
}

\author{
David Hue ${ }^{1}$, Christophe François ${ }^{2}$, Julien Dandois ${ }^{3}$ \\ ONERA-The French Aerospace Lab, 92190 Meudon, France \\ Anna Gebhardt ${ }^{4}$ \\ German Aerospace Center (DLR), Lilienthalplatz 7, 38108 Braunschweig, Germany
}

Keywords: High-lift, high bypass ratio turbofan engines, nacelle wake flow separation, active flow control, fluidic actuators, pulsed blowing jet

In take-off or landing conditions, the vortices emerging from the engine strake and pylon as well as from the internal and external slat tips of civil aircraft configurations can be the cause of the so-called nacelle wake flow separation. This phenomenon might be responsible for the wing stall and sudden lift loss; the effect is expected to increase with the coming up of enlarged nacelles and larger slat cutouts typical of ultra-high bypass ratio turbofan engines. In the framework of the European project AFLoNext, DLR and ONERA performed numerical studies focused on a realistic high-lift airplane geometry. Structured and unstructured grids were generated to perform RANS computations aimed at analyzing the uncontrolled flow features and determining relevant location and settings for active flow control systems. Constant blowing devices with different slot sizes, types and injection velocities were evaluated with RANS simulations over complete lift polars. The gains in $C L_{\max }$ were quantified; they range from 1 to $3 \%$ for momentum coefficients compatible with manufacturer requirements, the nacelle wake separation appearing at angles of attack one to two degrees higher than without control and the lift levels in post-stall conditions being significantly improved. Finally, unsteady RANS computations were carried out to investigate the potential of a pulsed blowing device. The gains in $C L_{\max }$ and flow separation containment obtained with the latter are similar to those of constant blowing devices which yet exhibit greater momentum coefficient and mass flow rate values.

\footnotetext{
${ }^{1}$ Engineer, Applied Aerodynamics Department, david.hue@ onera.fr.

${ }^{2}$ Engineer, Applied Aerodynamics Department, christophe.francois@onera.fr.

${ }^{3}$ Engineer, Applied Aerodynamics Department, julien.dandois@ onera.fr.

${ }^{4}$ Engineer, Transport Aircraft Department, anna.gebhardt@dlr.de.
} 


\section{Introduction}

The issue of nacelle wake flow separation occurring on aircraft wings at low flight speeds will be something to tackle with the coming up of enlarged nacelles typical of Ultra-High Bypass Ratio engines (UHBR). Recent studies, such as EUROLIFT I and II [1,2], demonstrated that the vortex system emerging from the engine strake and pylon as well as from the internal and external slat tips lead to a possibly massive separation on the main wing suction side at high angles of attack. This so-called nacelle wake separation is expected to be even more extended with the new UHBR nacelles since they require potentially larger slat cutout at the engine/wing junction.

As this flow separation in such take-off or landing conditions might be responsible for dramatic wing stall and associated lift loss, this topic is studied with persistence and the European project called AFLoNext (Active Flow Loads and Noise control on next generation wing), which was launched in 2013, includes activities focused on the handling of that phenomenon [3]. More specifically, the $2^{\text {nd }}$ work package of AFLoNext is dedicated to the study of Active Flow Control (AFC) technologies that could be applied to contain and delay the nacelle wake separation [4,5]; and even if the function of fluidic actuators always consists in adding momentum to the flow to enhance its resistance against separation, different AFC devices such as synthetic and constant or pulsed (unsteady) blowing jets $[6,7,8]$ have been considered in these investigations.

In the present CFD-oriented publication produced by DLR and ONERA, the German and French agencies involved in these AFLoNext activities, the focus will be on a realistic high-lift aircraft configuration including slats and flap deployed for landing conditions as well as a high bypass ratio engine. The AFC systems computed and assessed in this work are constant and pulsed blowing actuators. The first sections will describe the airplane geometry and the structured and unstructured grids used by the partners for their Navier-Stokes (NS) simulations. Then, a section will be dedicated to the study of the baseline configuration (i.e. without flow control), a necessary step to analyze the uncontrolled flow features and characteristics of flow separation development; this allows appropriate location and settings for the flow control devices to be determined. A highlight will be given to a 14-slot system that will be also considered in other following AFLoNext activities. The RANS (Reynolds Averaged NS) simulations aimed at evaluating the gains provided by the different constant blowing systems under review will be presented. Global and local physical variables such as lift, drag, and skin friction coefficients are used to quantify and explain the AFC effects. Finally, the Unsteady RANS (URANS) computations performed to assess the efficiency of a pulsed blowing system based on a rectangular signal will be shown.

\section{Geometries and Grids}

\section{A. The high-lift aircraft configuration}

In this work package of the European project AFLoNext, two configurations were considered by the different partners. Only the realistic one will be handled in this publication, it was computed by DLR and ONERA. This aircraft geometry is a high-lift semi-configuration (port wing) that includes internal and external slats, as well as a flap; these devices being deployed to match landing conditions. It also includes a high bypass ratio engine of next 
generation which imposes a large slat cut-out on the main wing leading edge. The engine itself is composed of a TFN, an internal plug and a strake on the inboard side. It is mounted on a pylon whose shape is specific to (U)HBR engines. The dimensions of the aircraft are the following: 46 meters long, $20 \mathrm{~m}$ of half-span, a mean aerodynamic chord of $5.15 \mathrm{~m}$, a reference surface $S_{\text {ref }}$ of $86 \mathrm{~m}^{2}$, and a nacelle external diameter of about $2.9 \mathrm{~m}$. These geometric features are visible in Figure 1 and Figure 2. It can be observed that this is a relatively complex aircraft configuration to be handled, especially considering the URANS issues.

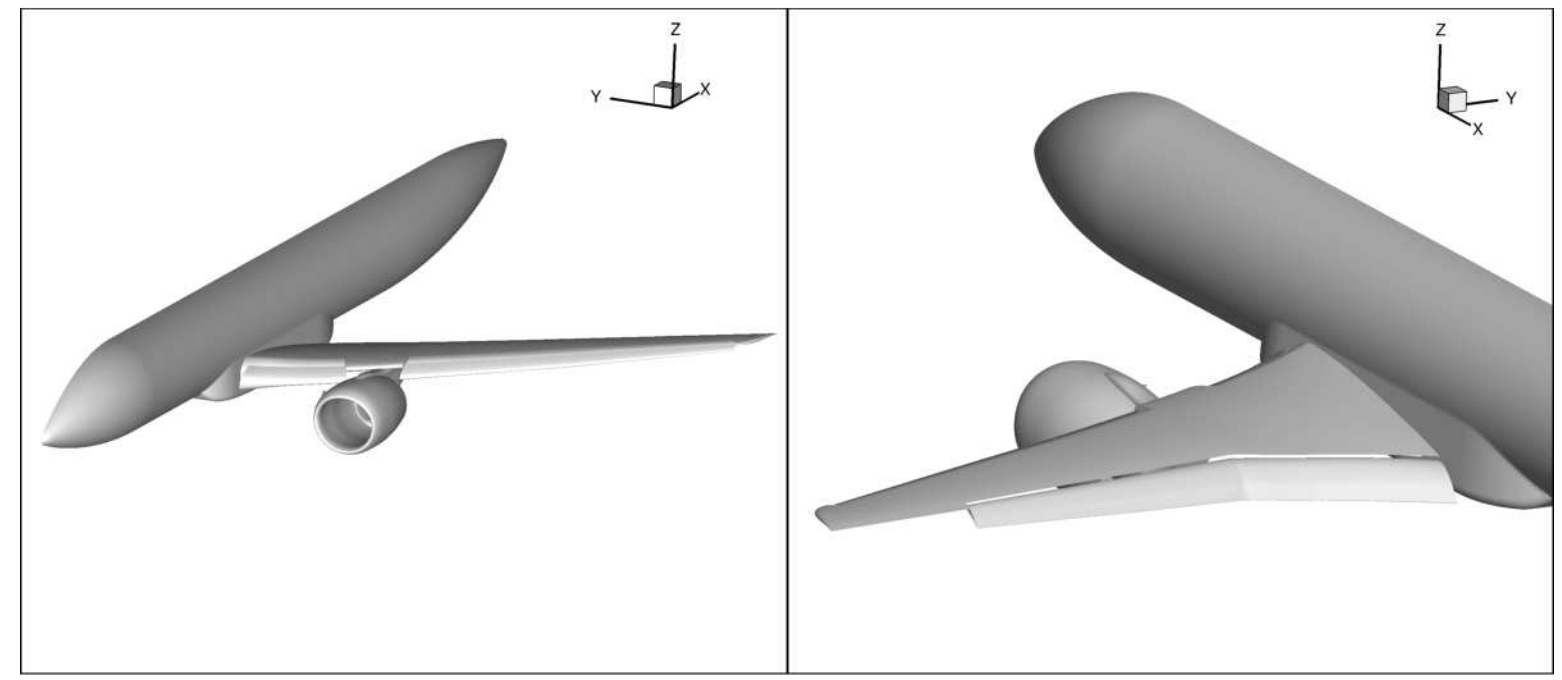

Figure 1: AFLoNext realistic configuration; a high-lift motorized (HBR type) aircraft.

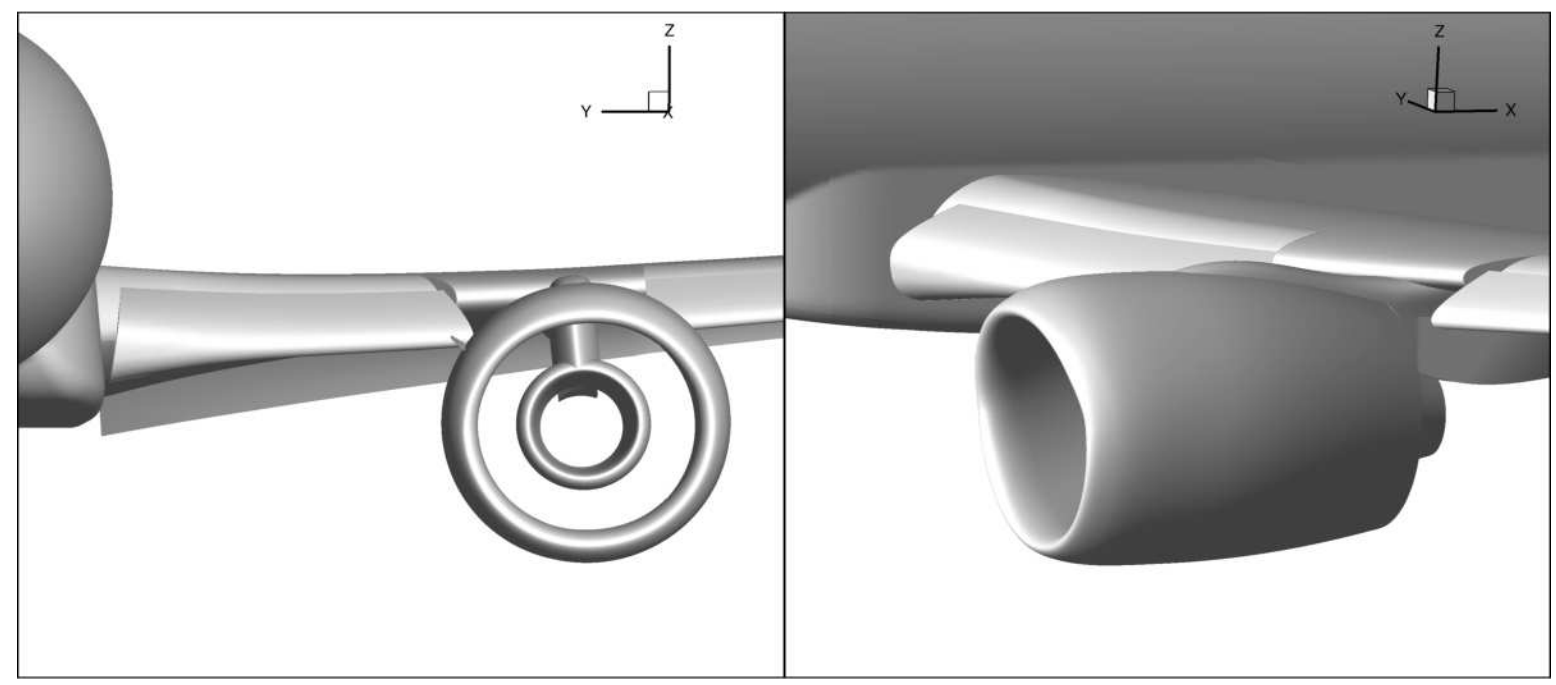

Figure 2: Focus on geometric features close to the engine/wing junction. 


\section{B. The structured overset grids}

To perform computations with a structured solver, such a complex geometry clearly justifies the use of overset techniques, also known as chimera [9]. Nevertheless, some specificities of the configuration, in particular the contacts between slats and wing at the engine/wing junction, made this overset meshing process a real challenge. The realistic AFLoNext configuration was handled by ONERA experts and, after several months of work, a complete overset grid assembly was successfully achieved.

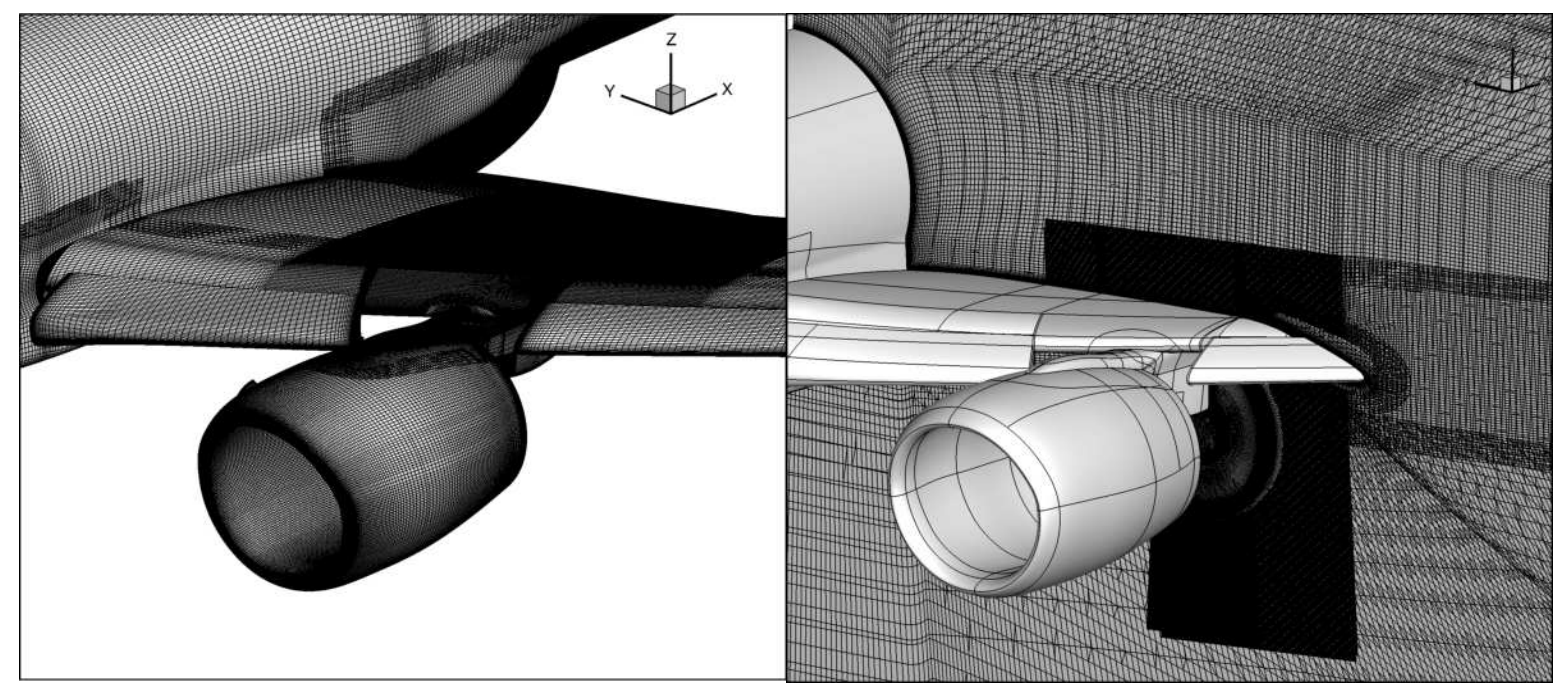

Figure 3: Structured grids on aircraft surfaces and refinement boxes in areas of interest.

Details about such procedures can be found in [10] but the basic idea is that the different overset elements are added gradually. In this case, the wing-body grid, which defines the whole computational domain, was treated first by using the meshing software ICEM Hexa [11] while the engine/pylon mesh was generated independently with POINTWISE [12]. Slat and flap meshes were also done separately. At last, the strake was included and refinement boxes were added in the areas of interest. Finally, the overset grid assembly (including blanking and overlapping steps) was completed with the in-house software Cassiopée [13].

The specificities of this overset mesh are illustrated in Figure 3 and Figure 4. The management of slat/wing contacts is handled by virtual solid blocks where the flow is numerically frozen; they allow the necessary overset interpolations between slat and wing meshes. It can also be noticed that collar grids have been used. They are located at junctions in order to precisely describe the element intersections, for instance between pylon and wing or pylon and nacelle. The best practices were applied in terms of grid quality (normalized first cell height $\mathrm{y}^{+}$, orthogonality at skin, low growth ratios) and overset assembly (consistency between overlapping grids, satisfactory interpolation areas). The final assembly exhibits no orphan/critical cells and no more than $0.02 \%$ of extrapolated cells, which is remarkable for such a configuration.

The whole mesh is composed of 70 million of structured cells in 13 different overset bases. The blanked cells are not removed from this count. The convergence behavior which is obtained with the complete mesh is satisfactory 
(considering the high-lift conditions). As an illustration, the $\mathrm{y}^{+}$distribution for aerodynamic conditions representative of the present study is given in Figure 5.

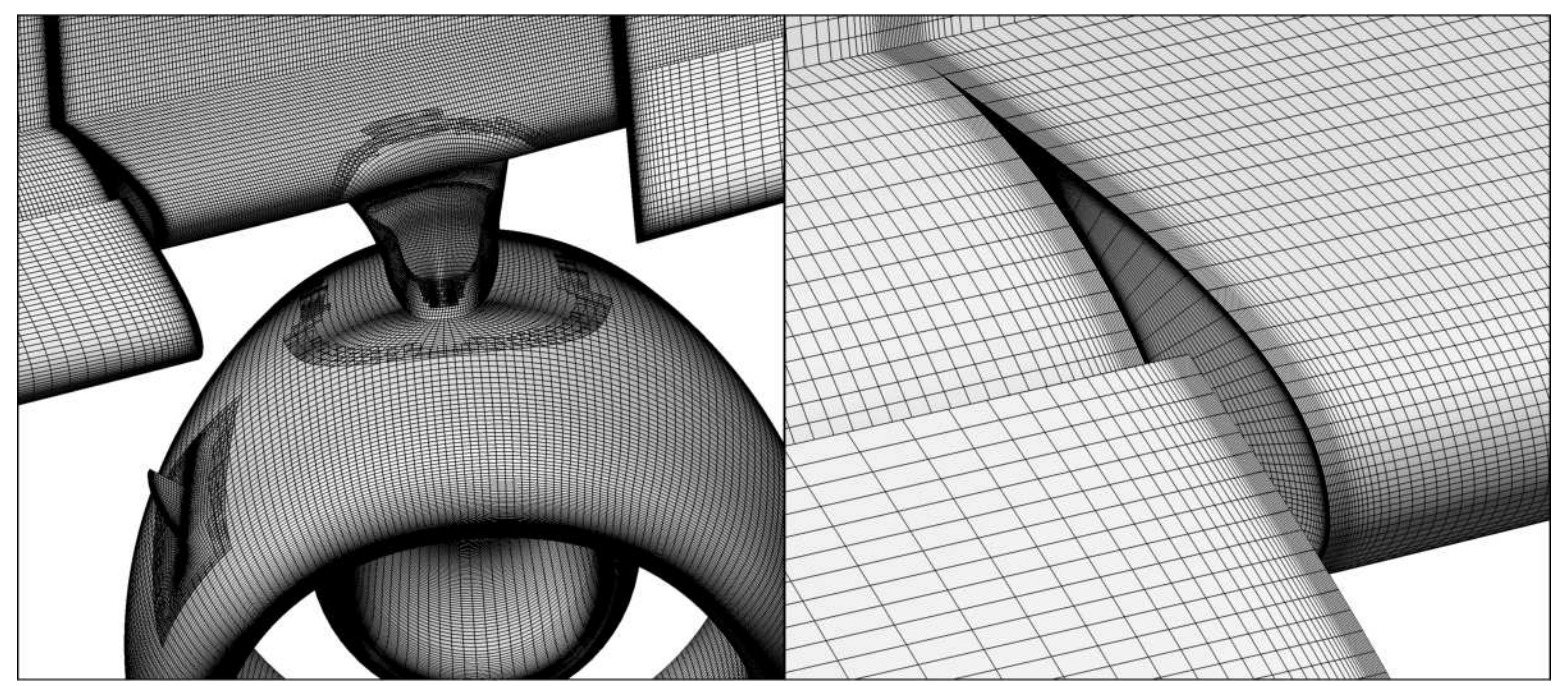

Figure 4: Focus on collar grids at engine/wing junction, and on contacts at slat/wing junction.

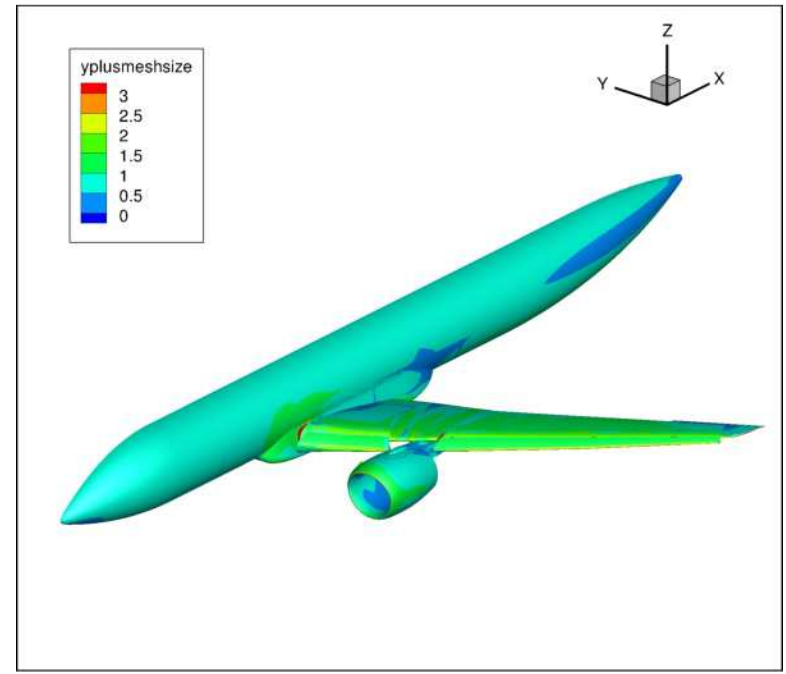

Figure 5: $\mathbf{y}^{+}$distribution of overset grids.

\section{The unstructured grids}

The unstructured grids were created with the grid generator SOLAR [14]. The surface is discretized by a quaddominant mesh on which quasi-structured hexahedron are generated to cover the boundary layer. The rest of the flow field is filled with tetrahedrons. Figure 6 shows the surface mesh of the whole configuration. In Figure 7, a detailed view of the mesh in the region of the nacelle and wing behind it are illustrated. The refinement of the slat 
and flap are visible. However, in contrast to the structured grid, there is no refinement over the wing downstream of the nacelle since with this mesh no flow control investigation in this region was scheduled.

The mesh has 20.4 million nodes and 29 hexahedron layers to resolve the boundary layer. In Figure 8 , the $\mathrm{y}^{+}$ distribution is shown. In comparison with the structured grid distribution in Figure 5, it can be observed that the near wall region with the first layer is a bit coarser resolved but is in the region of the wing still acceptable for the turbulence model used.

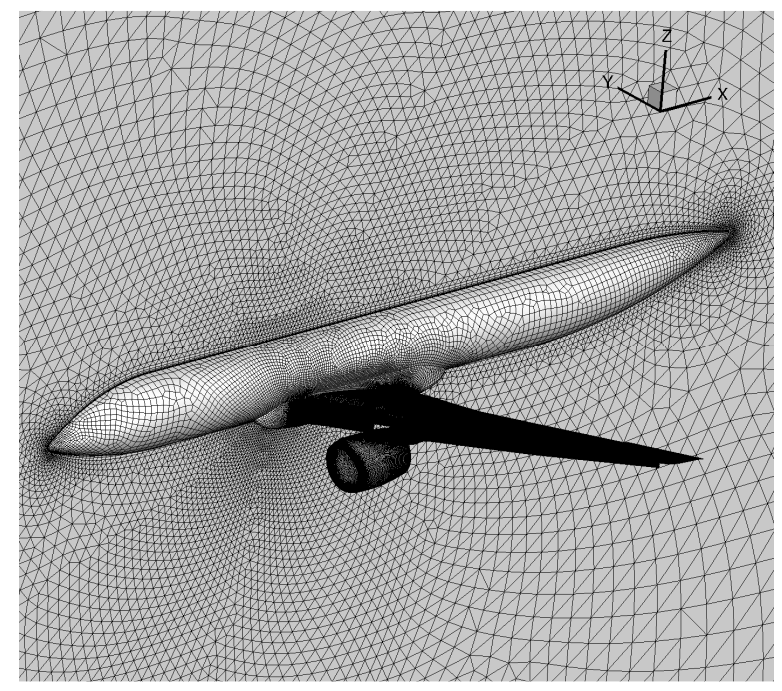

Figure 6: Overview of the unstructured grid.
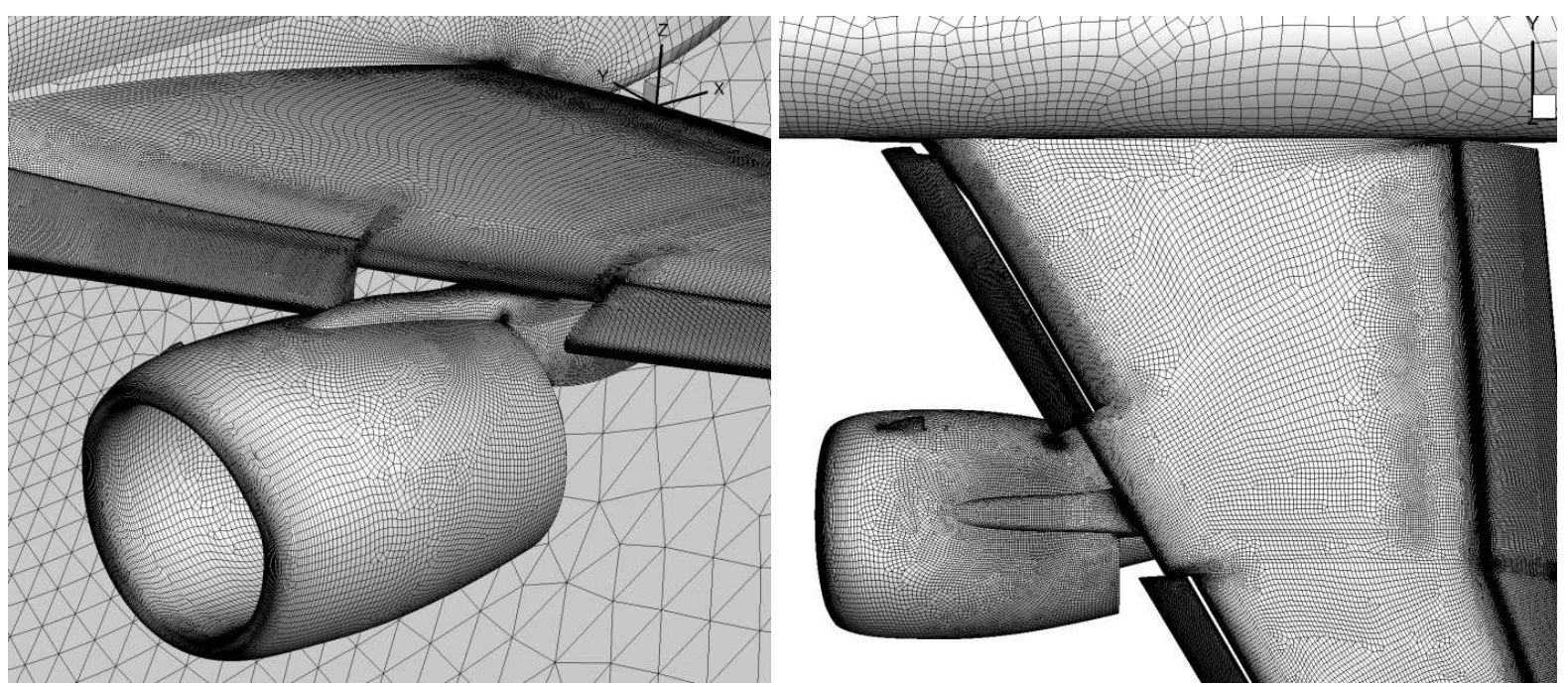

Figure 7: Detail view of the nacelle and wing unstructured grid. 


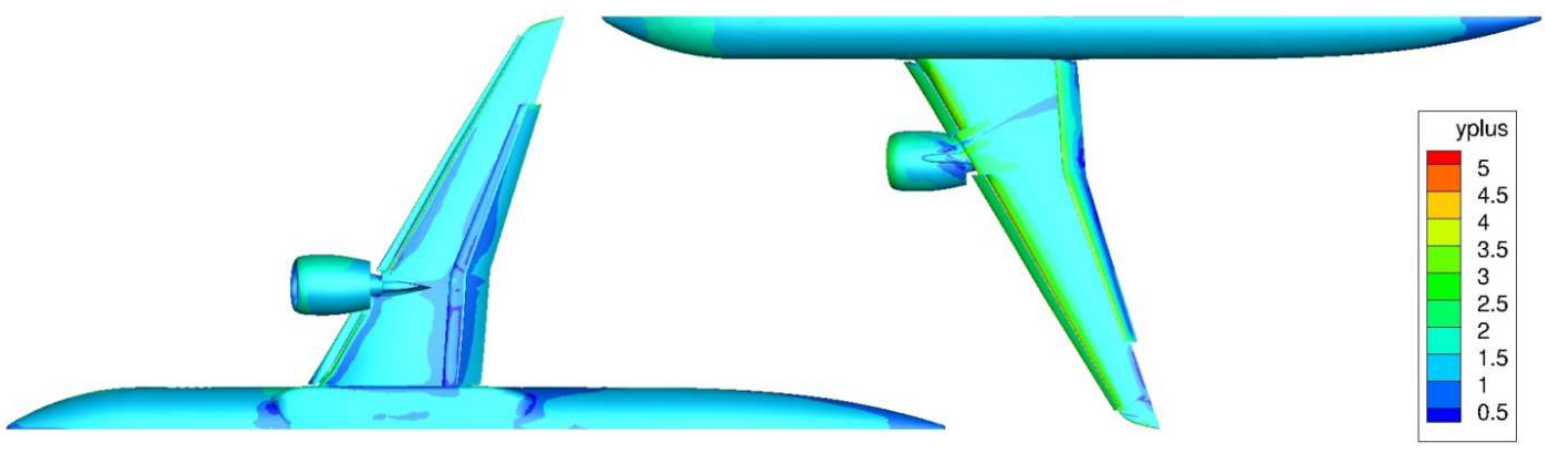

Figure 8: $\mathbf{y}^{+}$distribution of the unstructured grid.

\section{Navier-Stokes solvers and numerical considerations}

\section{A. elsA}

In this study, all the structured computations were performed with the structured ONERA-elsA Navier-Stokes solver [15]. This software uses a cell-centered Finite-Volume discretization on structured point-matched and overset meshes. Time integration is carried out by a backward-Euler scheme with implicit relaxation. Spatial discretization is achieved using a $2^{\text {nd }}$ order centered scheme of Jameson et al [16]. Multigrid techniques are used to accelerate the convergence. In this study, turbulence effects are simulated by the one-equation Spalart-Allmaras model [17]. Tests involving the Quadratic Constitutive Relation (QCR-2000) [18] were performed but it led to no significant effect. To adapt the numerical settings to the high-lift conditions, slight adjustments were considered compared to the standard elsA parameters generally used for cruise conditions. In particular, the artificial dissipation of the Jameson scheme was lightly increased.

As a first step, RANS computations were performed for the baseline configuration analysis (without flow control) and then for the constant blowing AFC calculations. Different lift and drag polars were completed. As it is common to proceed for high-lift polars, an initial computation was launched with a low angle of attack (typically $10^{\circ}$ ) to start from a fully attached flow and then a higher incidence was set to perform a restart using the previous solution and so forth. Figure 9 gives an illustration of the flux convergence process for RANS simulations with the lift $(C L)$ and drag $(C D)$ coefficients. For angles of attack at which the flow is attached $\left(10^{\circ}\right)$, the flux oscillation remains very limited. On the other hand, when substantial flow separations exist $\left(16^{\circ}\right)$, the fluxes can show some oscillations. In this case, the calculation shall be continued until the fluxes are stabilized around a constant mean value.

Then, some URANS simulations were carried out to assess the potential of unsteady blowing AFC systems. A pulsed blowing boundary condition (rectangular signal) was imposed. The Dual Time Stepping (DTS) method was chosen. The time derivate of the considered governing equations is discretized with a $2^{\text {nd }}$ order accurate backward Euler difference scheme, and the resulting algebraic system is solved by iterating to a steady state in an introduced 
fictitious time. The inner iteration strongly resembles the iteration for convergence to steady state, so that the techniques applied for efficient steady state convergence may be applied (multigrid method, local time step). Due to long convergence processes, only two computations were performed. These two calculations asked more than one hundred of fifteen-hour jobs each to go through the transitional regime and achieve constant mean values despite relatively high time steps. More details (time step and number of inner iterations) for each case will be given in the dedicated section.

All the elsA simulations were executed on a Silicon Graphics cluster (SGI ICE 8200) in distributed mode, using 128 to 256 cores.

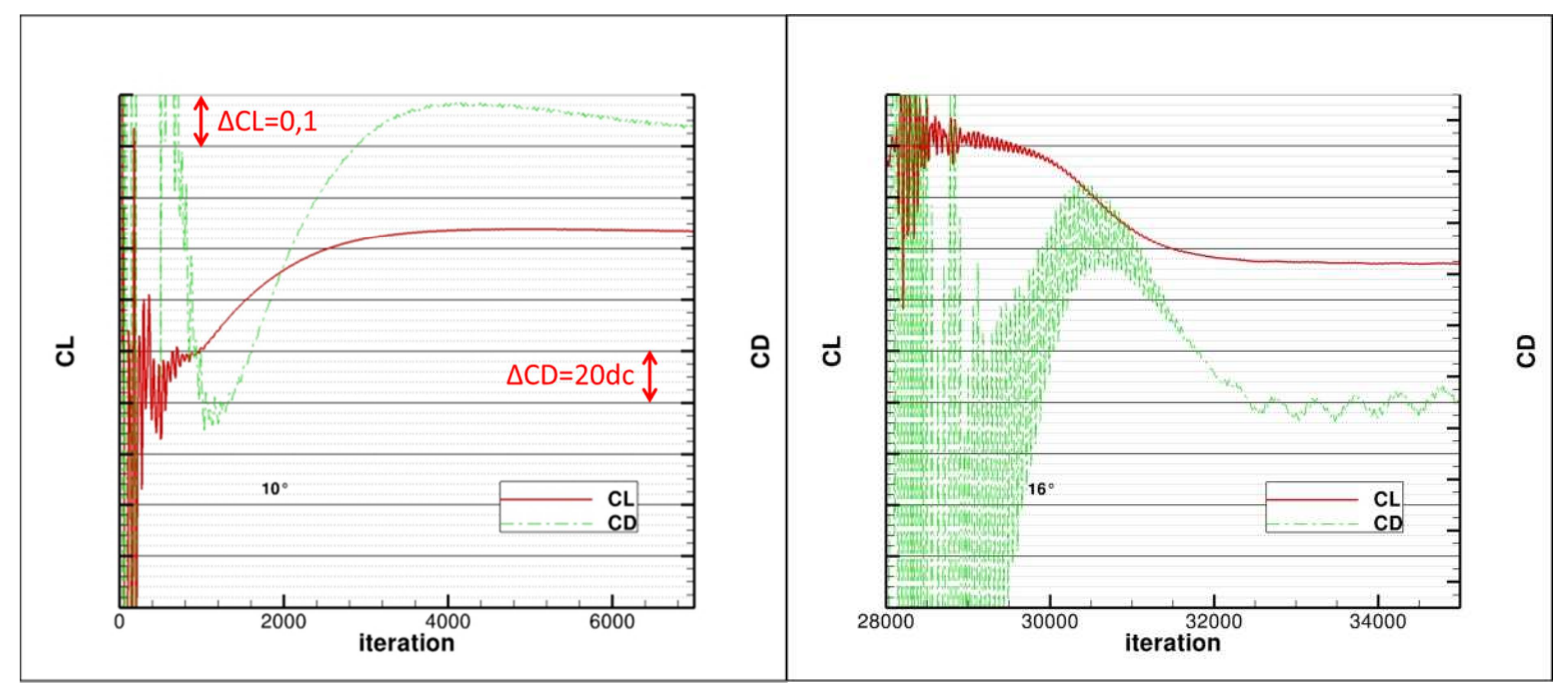

Figure 9: Numerical convergence of lift and drag coefficients $\left(C D\right.$ in drag counts i.e. $\left.1.10^{-4}\right)$ in elsA; same relative scales in both figures.

\section{B. TAU}

The DLR computations were carried out with the flow solver TAU, release 2013.2.0, which was mainly developed in-house [19]. TAU is a finite-volume vertex based solver with an edge-based data structure that employs hybrid unstructured grids. Only steady RANS computations were conducted with TAU in this study.

Some convergence problems with the flow calculation were observed. Due to this, the solver was switched to a second order AUSMDV upwind scheme [20] with scalar dissipation for the discretization of the inviscid fluxes. A Runge-Kutta scheme was applied for the time integration to steady state. For convergence acceleration, a three-level multigrid scheme was used. The Spalart and Allmaras negative (SA-neg) turbulence model [17] was applied and a fully turbulent flow without any transition was assumed.

In the same way as the structured elsA computations, the TAU calculations were started at a lower angle of attack of $10^{\circ}$. The subsequent angle of attack was always computed as a restart of the previous solution. With increasing area of separated flow also, the convergence starts to show oscillations of the lift and drag coefficients for angles of attack of $16^{\circ}$ and higher as often experienced for such high-lift configurations. 


\section{RANS simulations without flow control}

Prior to investigating the potential of flow control, it was necessary to perform computations of the configuration without any control system. This configuration will be referred to as the baseline in the following text. The analysis of flow field on the baseline is obviously of prime importance to determine the future AFC position and settings in a relevant way.

The aerodynamic conditions that are considered are the following: Mach number of 0.20 , Reynolds number based on the mean aerodynamic chord of 24 million, and angles of attack ranging from 8 to $20^{\circ}$.

First, the global lift polars obtained by DLR and ONERA for this baseline configuration are shown in Figure 10. For confidentiality reasons, as it will be the case for this type of figures, the absolute scales are not indicated but the quantified deltas are given for each variable.

The results that have been achieved both by TAU and elsA computations show the classical characteristics of low-speed and high-lift aircraft calculations: the maximum lift coefficient value $C L_{\max }$ is achieved for angles of attack close to $15^{\circ}$. Its absolute value is typical of such configurations (greater than 2.0). After the linear region and $C L_{\max }$ point, the lift drops to a minimum value and then slightly grows for higher angles of attack despite a massive flow separation. Considering this not straightforward issue of high-lift prediction, it can be noticed that DLR and ONERA curves show a good agreement. Only minor differences can be observed: the $C L_{\max }$ value of ONERA is 0.05 higher $(+2 \%)$ and the $C L$ drop occurs about $0.5^{\circ}$ later. This good agreement on the same configuration between different grids and solvers is a valuable cross-comparison that can be considered as a kind of CFD validation.

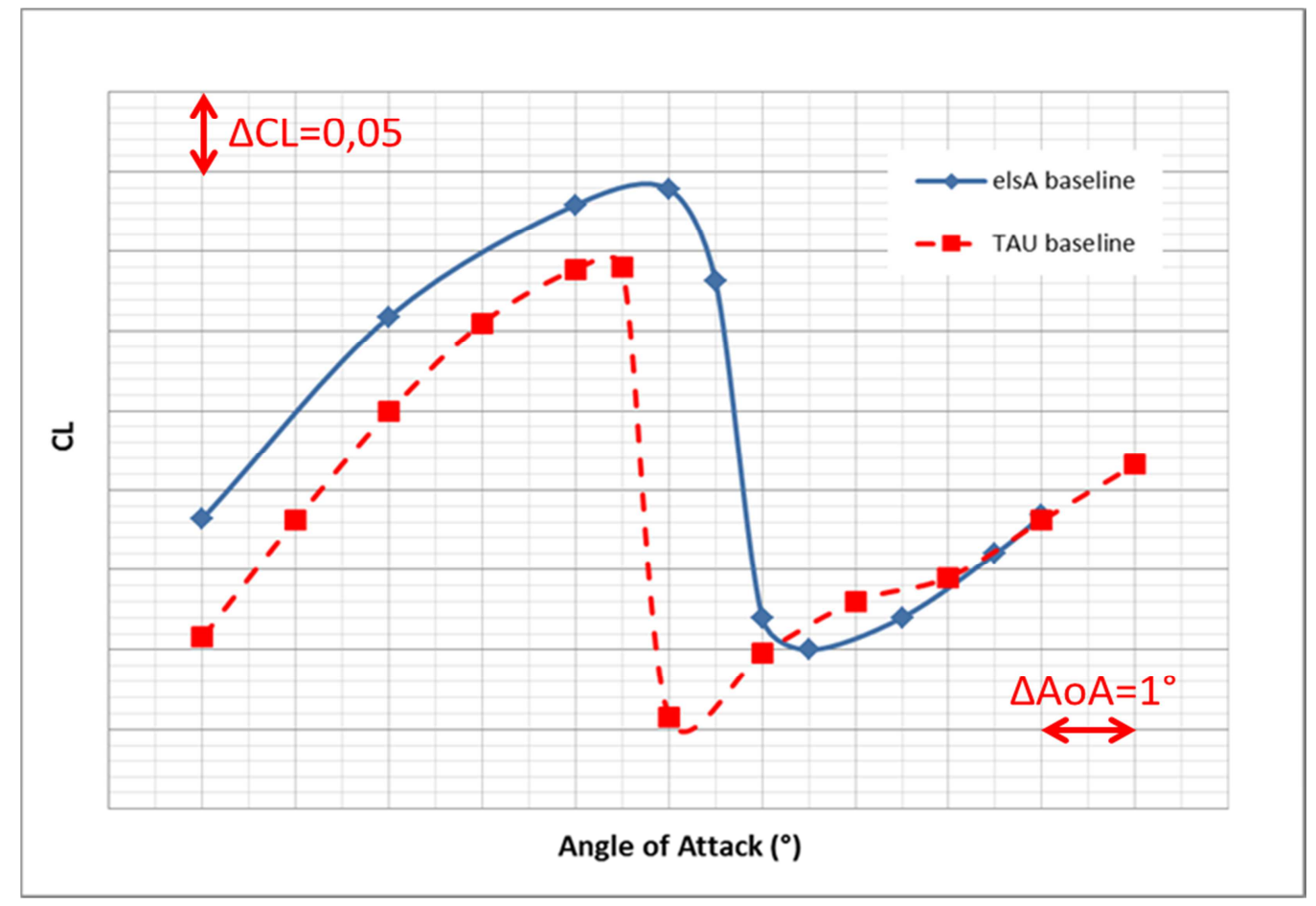

Figure 10: $C L(A o A)$; baseline configuration; elsA and TAU. 
To better understand the above lift polar curves, some local analyses obtained with elsA are presented in Figure 11. It shows the skin friction coefficient in the streamwise direction $(C f x)$ as well as the friction lines over the suction side of the wing downstream of the engine for angles of attack from 14 to $18.5^{\circ}$. It can be noticed that a limited flow separation exists on the wing/pylon junction even at the lowest angles of attack. On the other hand, the flow on the wing is fully attached until $15^{\circ}$. Slats and flap exhibit completely attached flow over the whole polar. The vortex structures are visible with the friction lines but will be better shown further. The vortices emerge from internal and external slat cutouts and from the wing/pylon junction. While the angle of attack is increasing, these structures tend to adopt crossflow directions in the rear part of the wing. The massive flow separation responsible for the lift drop starts to appear at $15^{\circ}$ at the main wing trailing edge. Its development is sudden: at $16^{\circ}$ of incidence, its extent is already substantial. If the angle of attack increases again, the flow separation from the trailing edge joins the one of the leading edge at wing / pylon junction. Nevertheless, for angles higher than $18^{\circ}$, it seems that the flow separation does not grow anymore.

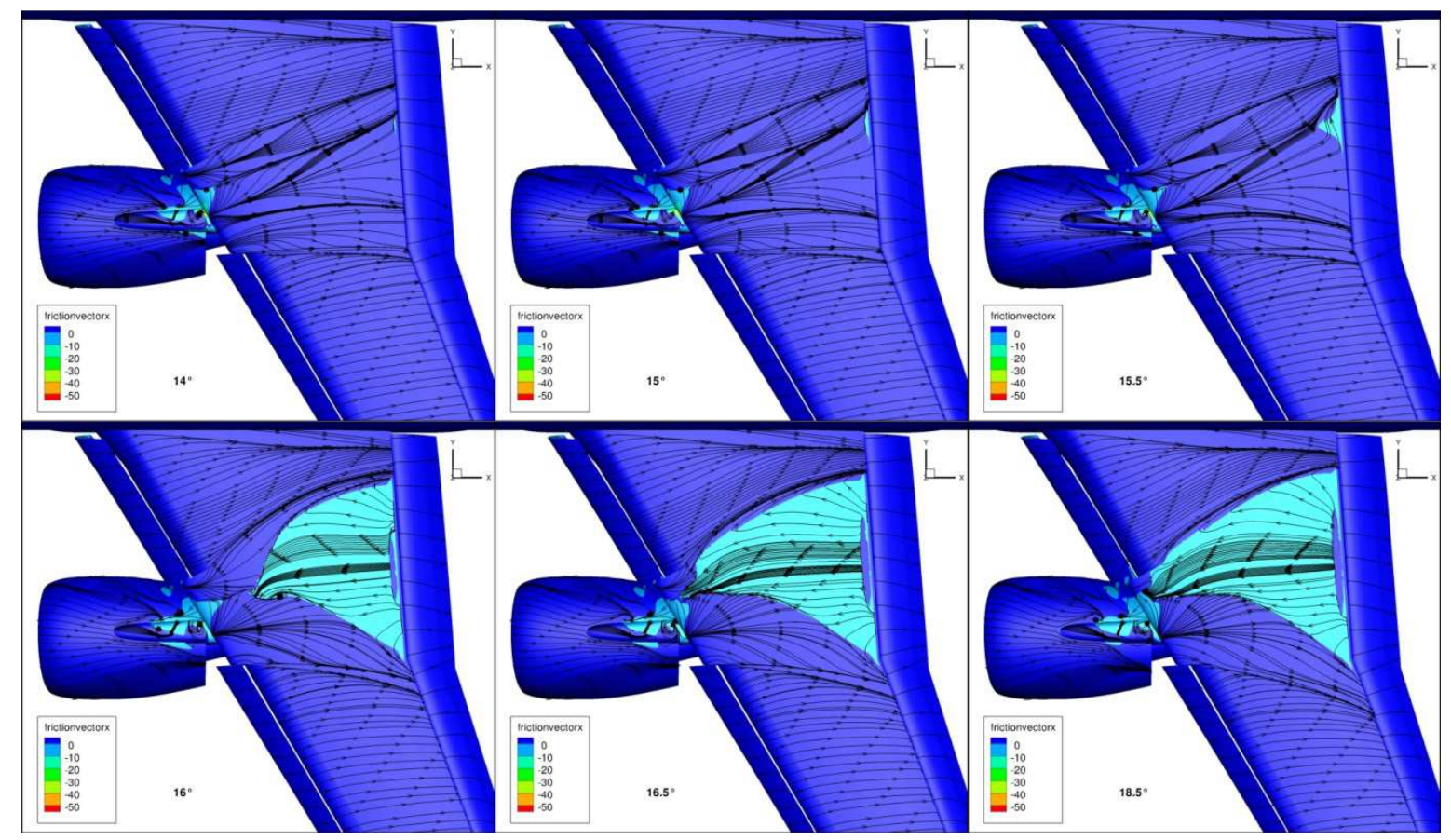

Figure 11: $C f x$ distribution and friction lines; baseline configuration; 14 to $18.5^{\circ}$; elsA.

The equivalent DLR results focusing on friction are shown in Figure 12. Two angles of attack are presented: $14^{\circ}$ before the $C L$ drop and $15^{\circ}$ for which a massive flow separation is predicted. Here again, it can be noticed that TAU and elsA results are in good agreement: the local flow patterns are very similar. A difference thought is that the flow separation predicted by elsA is a bit more extended in the outboard part of the wing and therefore it seems slightly greater. 


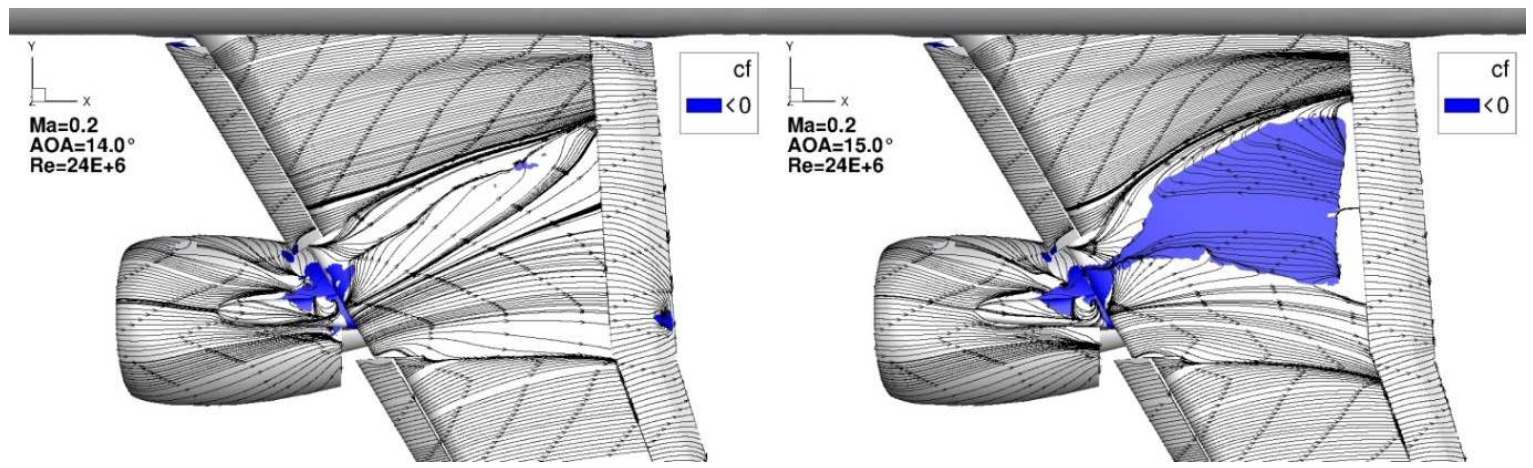

Figure 12: $C f x$ distribution and friction lines; baseline configuration; 14 and $15^{\circ}$; TAU.

Pursuing with finer means of local analyzes, the Q-criterion is then used to visualize the vortex system which emerges from the different elements: slats, pylon, strake. A vortex is characterized by a second invariant of the stress tensor $Q$ positive, with $Q$ defined as $1 / 2 *\left(\Omega_{\mathrm{ij}} \Omega_{\mathrm{ij}}-S_{\mathrm{ij}} S_{\mathrm{ij}}\right)$, where $\Omega$ is the vorticity and $S$ is the rate-of-strain $(Q$ represents vortices as areas where the vorticity magnitude is greater than the magnitude of rate-of-strain). Figure 13 depicts the results of elsA computations at 14 and $16.5^{\circ}$. It can be seen that the strake clockwise vortex in particular is fairly well captured: this is due to satisfactory mesh refinement and good overset interpolations in this area. The strake vortex trajectory is quite far from the wing surface, especially for incidences close to the $C L$ drop. Consequently, the effective impact of the strake can be questioned. Considering the other vortices, the great ones coming from the slat cutouts are clearly visible (they are the most external). And coming from the wing/pylon junction, several vortices can be observed, they tend to group together with the angle of attack increase. At $16.5^{\circ}$, with the massive flow separation, it seems that the vortices adopt more ascendant trajectories and do not extend much further over the wing as they did at $14^{\circ}$ (except the one from the outboard slat cutout).

To compare these features with the DLR computations, the equivalent outcome is given in Figure 14. The angle of attack is the one of the stall for TAU: $14.5^{\circ}$. One can observe a satisfactoy agreement between DLR and ONERA figures, especially for the external slat vortex. The effect of the mesh refinment over the wing used for the elsA computations is visible here when comparing with TAU. The elsA results show a better resolution and propagation of the vortices. The strake vortex for example seems to adopt the same trajectory as in Figure 13 but is rapidly dissipated. 


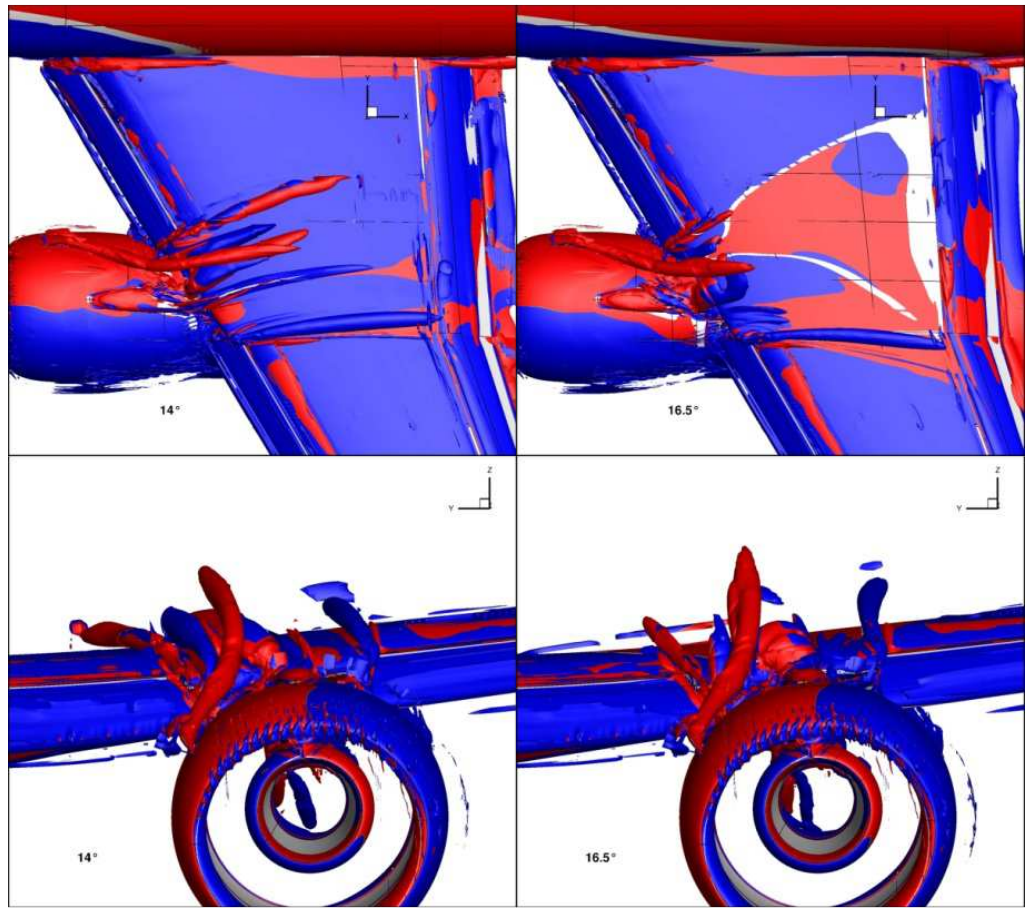

Figure 13: Q-criterion colored by vorticity-x (red: clockwise / blue: anti-clockwise); 14 and $16.5^{\circ}$; elsA.

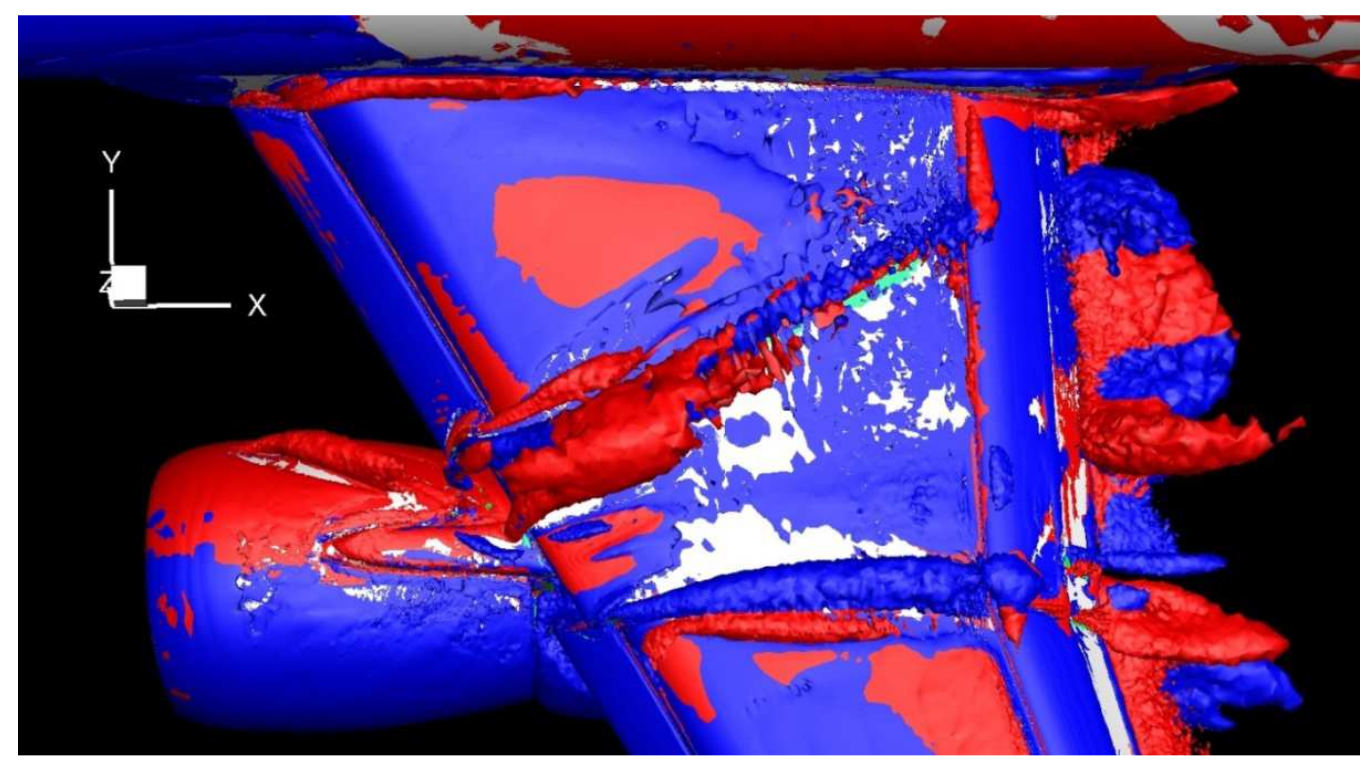

Figure 14: Q-criterion colored by vorticity-x; $14.5^{\circ}$; TAU.

Concluding this section focused on the baseline configuration, it can be said that the global and local agreement between elsA and TAU calculations gives good confidence in these first numerical results: the uncontrolled flowfield patterns have been clearly determined so that appropriate flow control systems can be defined. 


\section{The active flow control systems}

Based on the previous computations and also on studies carried out by other partners of the project, several flow control systems were defined and evaluated by DLR and ONERA.

Figure 11 presented above illustrates the characteristics of the flow separation which is to be handled by the AFC system. As it can be observed, a natural position for the flow control devices is the part of the main wing leading edge between internal and external slats. Actually, this position would be approximately the same as the one of the slat/wing slot if the slat was not cut around the pylon location. Besides, this AFC system position is compatible with installation constraints provided by the aircraft manufacturer.

Moreover, DLR studies [5] showed that implementing AFC devices in the outboard part of the leading edge between slats is not aerodynamically effective; this can be expected considering Figure 11. Considering the blowing angle (i.e. the angle between the blowing velocity direction and surface tangent), the usual value of $30^{\circ}$ was used. As a consequence, all the AFC systems treated in this study exhibit the same position, same spanwise and same blowing angle:

- $10 \%$ chord behind the main wing leading edge,

- only in the inboard part of the leading edge between slats,

- $\quad 30^{\circ}$ of blowing angle.

These features of the AFC systems that are investigated can be seen in Figure 15 and Figure 16. In Figure 15 is added a slice (wing section orthogonal to the leading edge) that will be used in section VI.

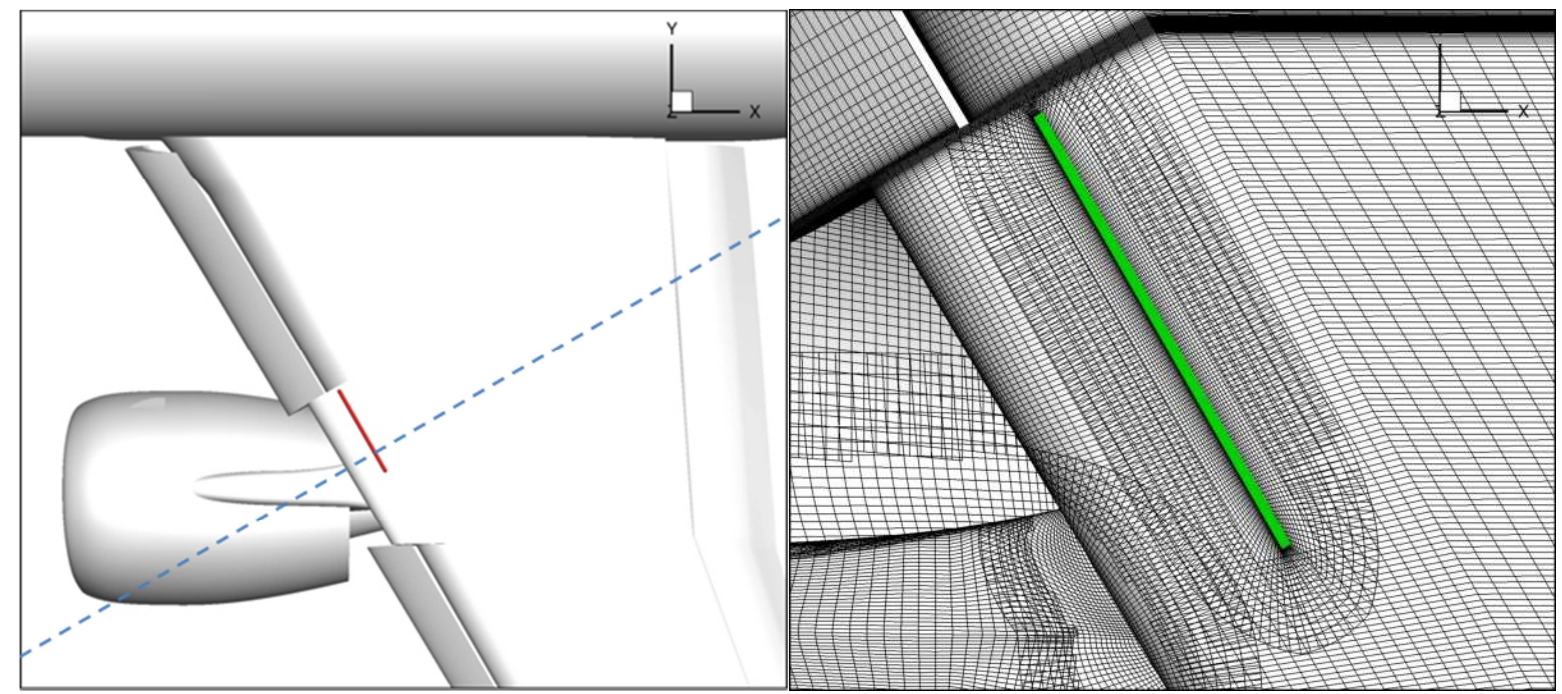

Figure 15: Position and initial grid of AFC systems. 


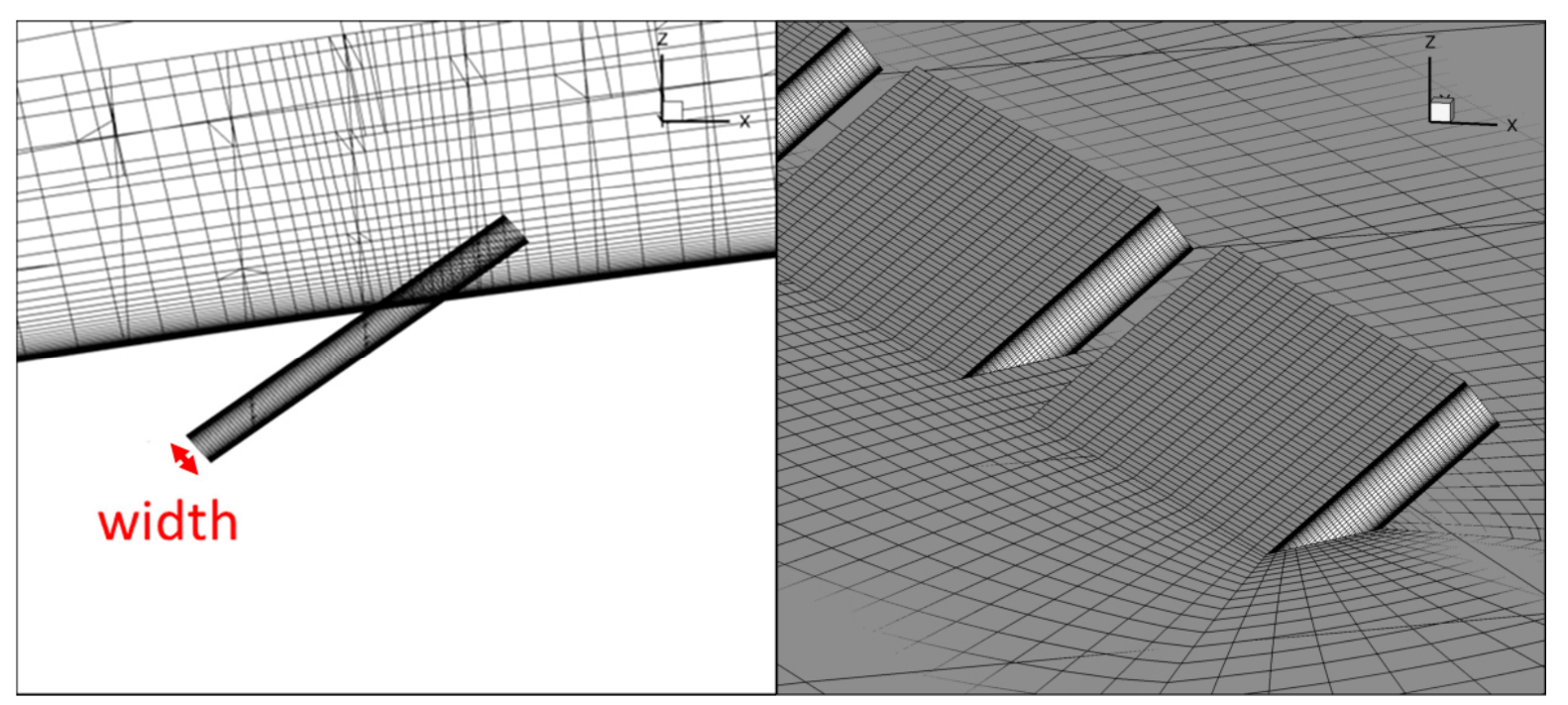

Figure 16: Wing section and isometric view showing the initial slot grids.

Considering the aspects of the AFC system modelling, it can be observed, especially in Figure 16, that the slot(s) from which the blowing velocity comes is fully described by an internal grid. This is not only a boundary condition applied on the wing surface. The grids of the internal slot(s) and the one that is added around the slot(s) are well refined. Typically, there are several tens of points in normal and streamwise directions and for segmented slots, between 10 and 20 points in the spanwise direction for each slot according to the slot grid refinement level. The number of points in the spanwise direction is limited because it must be chosen to be consistent with the wing mesh in this area in order to obtain satisfactory overset interpolations. The condition of injection (mass flow rate and orientation) is imposed at the inside tip of the slot and the development of boundary layers is captured with a relevant Navier-Stokes grid on upper and lower slot surfaces.

Table 1 shows the different AFC systems that were studied in this work. At this stage, some variables relative to the flow control settings must be introduced. In particular, the momentum coefficient $C_{\mu}$, which represents a normalized quantification of the actuation force over the flow, is defined as follows:

$$
C_{\mu}=\frac{1}{D C} \frac{\dot{\bar{m}} \bar{U}_{j}}{\frac{1}{2} \rho_{\infty} U_{\infty}{ }^{2} S_{r e f}} \quad \text { Eq. } 1
$$

where $D C=\mathrm{t}_{\text {active }} / \mathrm{t}_{\text {cycle }}$ is the duty cycle, $\dot{m}$ is the jet mass-flow rate, $U_{\mathrm{j}}$ is the jet peak velocity, $\dot{\bar{m}}$ and $\bar{U}_{j}$ being their time averages, $\rho_{\infty}$ and $U_{\infty}$ are the infinite flow density and velocity, and $S_{r e f}$ is the aircraft reference surface.

As visible in Table 1, two slot widths were tested: $2 \mathrm{~mm}$ with different blowing velocities ( $\mathrm{n}^{\circ} 1$ and 2 ) and $6 \mathrm{~mm}$ ( $n^{\circ} 3$ to 7 ). The first computations were performed with one long continuous slot and then it was segmented in the spanwise direction. First, in 7 slots and then, it was divided in 14 slots to better match real AFC systems evaluated in AFLoNext. To move from 7 to 14 slots, the surrounding slot grid had to be extended and refined as shown in Figure 17. It allowed a grid effect study on the 7-slot device to be performed ( ${ }^{\circ} 4$ and 5). Then, the 14-slot device (see Figure 18) was calculated in RANS constant blowing mode $\left(n^{\circ} 6\right)$. And finally, it was computed in pulsed blowing mode (or Pulsed Jet Actuation PJA) via URANS simulations ( ${ }^{\circ} 7$ ). The $C_{\mu}$ values for all these AFC systems range 
from 0.09 to $0.26 \%$, corresponding to mass flow rates and blowing velocities respectively ranging from 0.85 to 2.56 $\mathrm{kg} / \mathrm{s}$ and from 250 to $315 \mathrm{~m} / \mathrm{s}$. These values are compatible with current flow control actuator capabilities and a mass flow rate of $1 \mathrm{~kg} / \mathrm{s}$ is typically acceptable considering industrial requirements.

Table 1: Features of AFC systems.

\begin{tabular}{ccccccccc}
\hline $\mathbf{N}^{\circ}$ & Grid level & Segmented & $\begin{array}{c}\text { Number of } \\
\text { slots }\end{array}$ & $\begin{array}{c}\text { Slot } \\
\text { length } \\
(\mathbf{m m})\end{array}$ & $\begin{array}{c}\text { Slot } \\
\text { width } \\
(\mathbf{m m})\end{array}$ & $\begin{array}{c}\text { Peak blowing } \\
\text { velocity }(\mathbf{m} / \mathbf{s})\end{array}$ & $\begin{array}{c}\text { Mean mass } \\
\text { flow rate } \\
\mathbf{( k g / s})\end{array}$ & $\mathbf{C}_{\mu}(\%)$ \\
\hline $\mathbf{1}$ & initial & No & 1 & 1250 & 2 & 250 & 0.85 & 0.09 \\
$\mathbf{2}$ & initial & No & 1 & 1250 & 2 & 315 & 1.16 & 0.15 \\
$\mathbf{3}$ & initial & No & 1 & 1250 & 6 & 250 & 2.56 & 0.26 \\
$\mathbf{4}$ & initial & Yes & 7 & 100 & 6 & 250 & 1.45 & 0.15 \\
$\mathbf{5}$ & refined & Yes & 7 & 100 & 6 & 250 & 1.45 & 0.15 \\
$\mathbf{6}$ & refined & Yes & 14 & 70 & 6 & 250 & 2.00 & 0.21 \\
$\mathbf{7}$ & refined & Yes & 14 & 70 & 6 & 250 & 1.00 & 0.10 \\
\hline
\end{tabular}

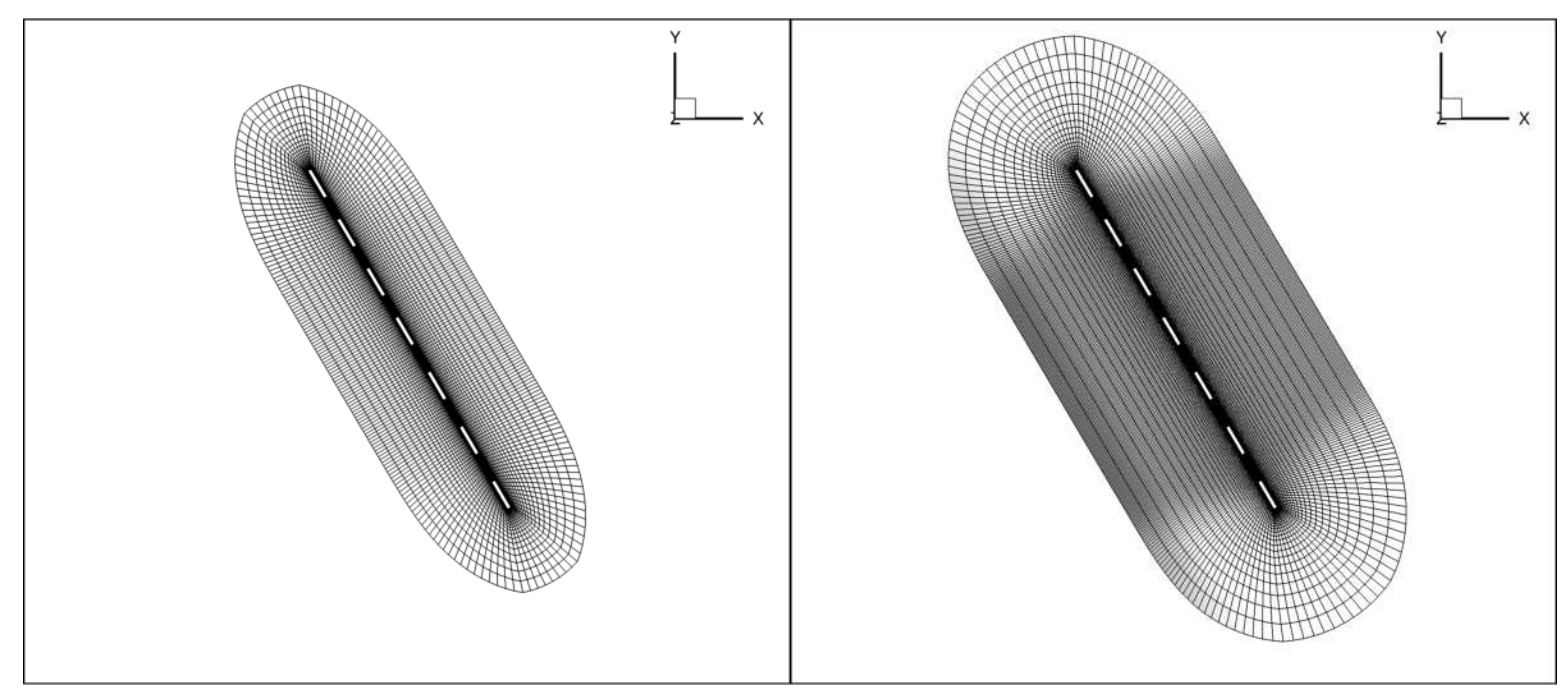

Figure 17: Refinement and extension of the grid surrounding the slot.

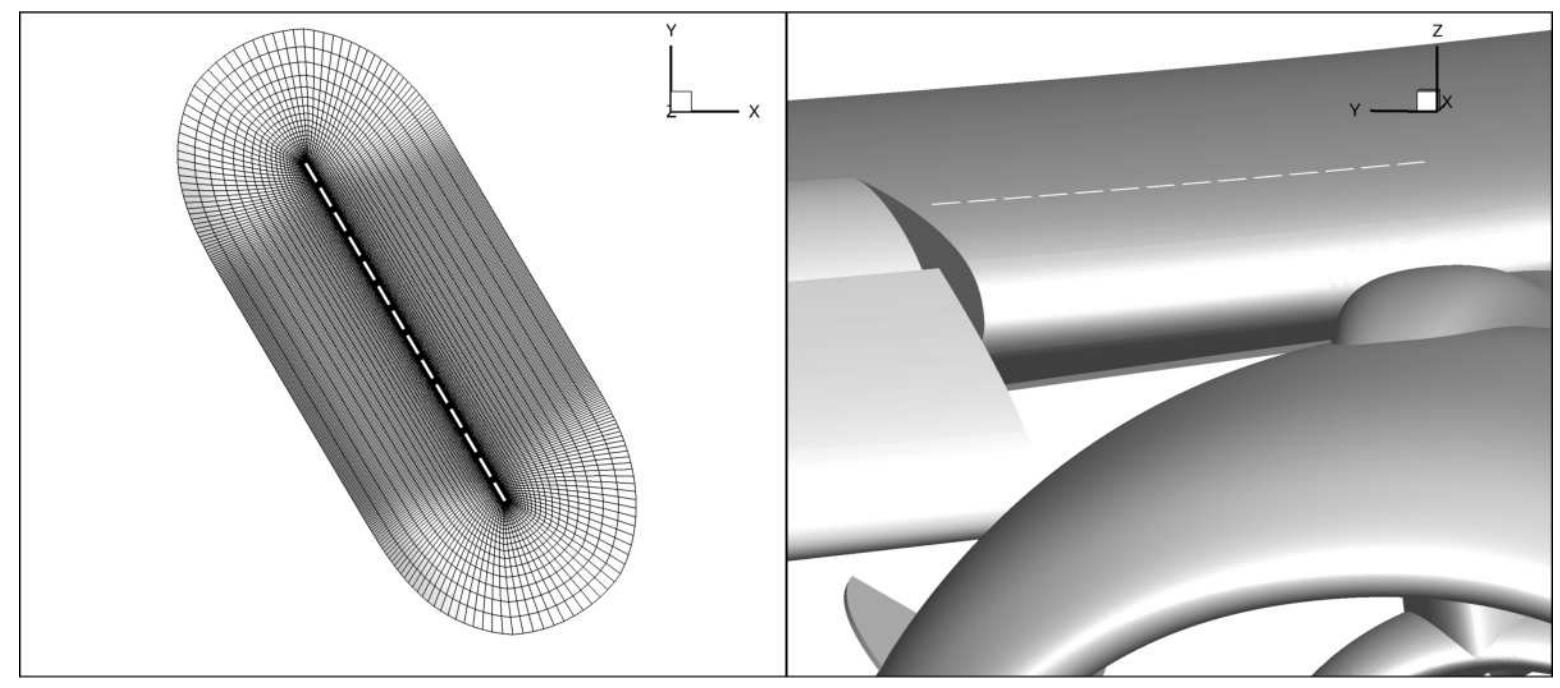

Figure 18: The 14-slot system and its implementation on the aircraft. 
Some additional details are given here concerning the last AFC device ( $\mathrm{n}^{\circ} 6$ and 7). It is composed of 14 slots of $70 \times 6 \mathrm{~mm}$ with inter-spaces of $20 \mathrm{~mm}$. It represents a length of $1250 \mathrm{~mm}$ in the spanwise direction. For the final case $\left(\mathrm{n}^{\circ} 7\right)$, the 14-slot device is used as a pulsed jet system. The blowing frequency is $60 \mathrm{~Hz}$ (it has been determined by other partner studies and following manufacturer constraints), the signal being rectangular, and the duty cycle is 0.5. Moreover, the slots blow alternatively: there is a phase shift of $\pi$ between consecutive slots. The effect can therefore be compared to the one of a sweeping jet with two output orifices. Figure 19 represents the blowing velocities over a period at the exit of slots 13 and 14 (outboard side).

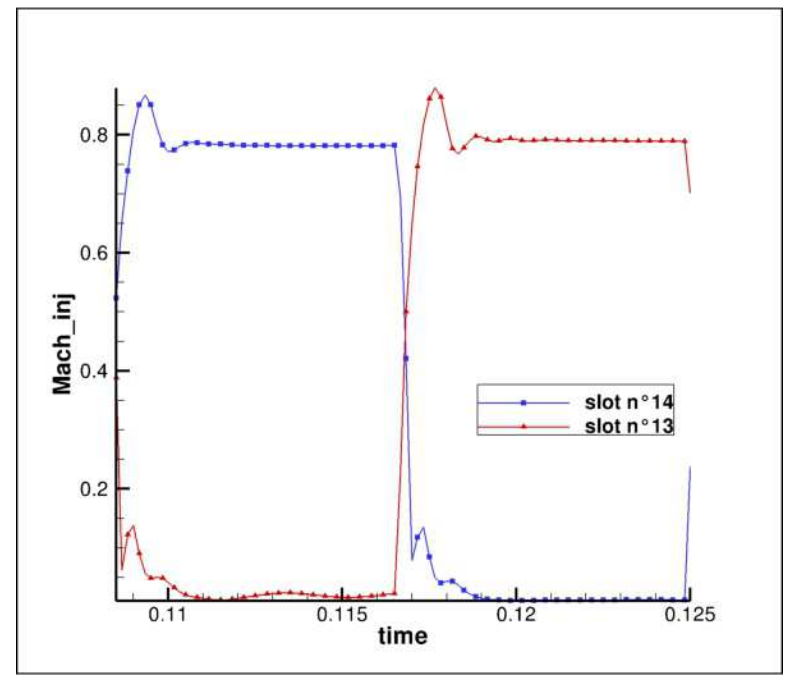

Figure 19: Blowing velocities of slots 13 and 14 for the device $\mathbf{n}^{\circ} 7$.

\section{RANS simulations with constant blowing flow control}

Only the AFC systems $n^{\circ} 1$ to 6 in Table 1 are addressed in this section. Besides, only ONERA performed AFC computations on the considered configuration. As a consequence, all the results presented below are obtained with the elsA solver. The aerodynamic conditions remain the same as in section IV.

Concerning the performance assessment of the different AFC systems and more specifically the global lift coefficients, the results are shown in Figure 20. It can be noticed that some points are referenced as URANS, they shall not be considered until the next section, they have been added only in order not to duplicate this figure.

The baseline configuration presented in Figure 10 is given here for comparison purposes. Also, red points are visible. They correspond to computations of the baseline but with the surrounding slot grid added. It means that there is no slot (no hole in the wing surface) but only the grid that will host the AFC system (see Figure 15). This is only a check of a potential grid effect. As it can be noticed, the results that were obtained show no grid effect over the whole polar. 
The different AFC systems are presented according to their $C_{\mu}$ values, the other characteristics can be read in Table 1. The first AFC device is a continuous slot of $2 \mathrm{~mm}$ with a low $C_{\mu}$ close to $0.09 \%$. This setup is not powerful enough to obtain a significant gain compared to the baseline configuration. However, the lift levels that are recorded after stall are higher with AFC on, even with this device: at $17^{\circ}$, the lift coefficient is increased by $+4 \%$.

The second AFC system is still a $2 \mathrm{~mm}$ continuous slot but with a greater blowing velocity which leads to a $C_{\mu}$ value of $0.15 \%$. It can be seen that some lift gains are obtained this time. The $C L_{\max }$ is slightly increased $(+0.025)$ and it is achieved for an angle of attack of $16^{\circ}$ instead of 15 . Moreover, after stall, once the flow separation is massively developed, the lift level remains relatively strong compared to the baseline curve $\left(+5 \%\right.$ at $\left.17^{\circ}\right)$.

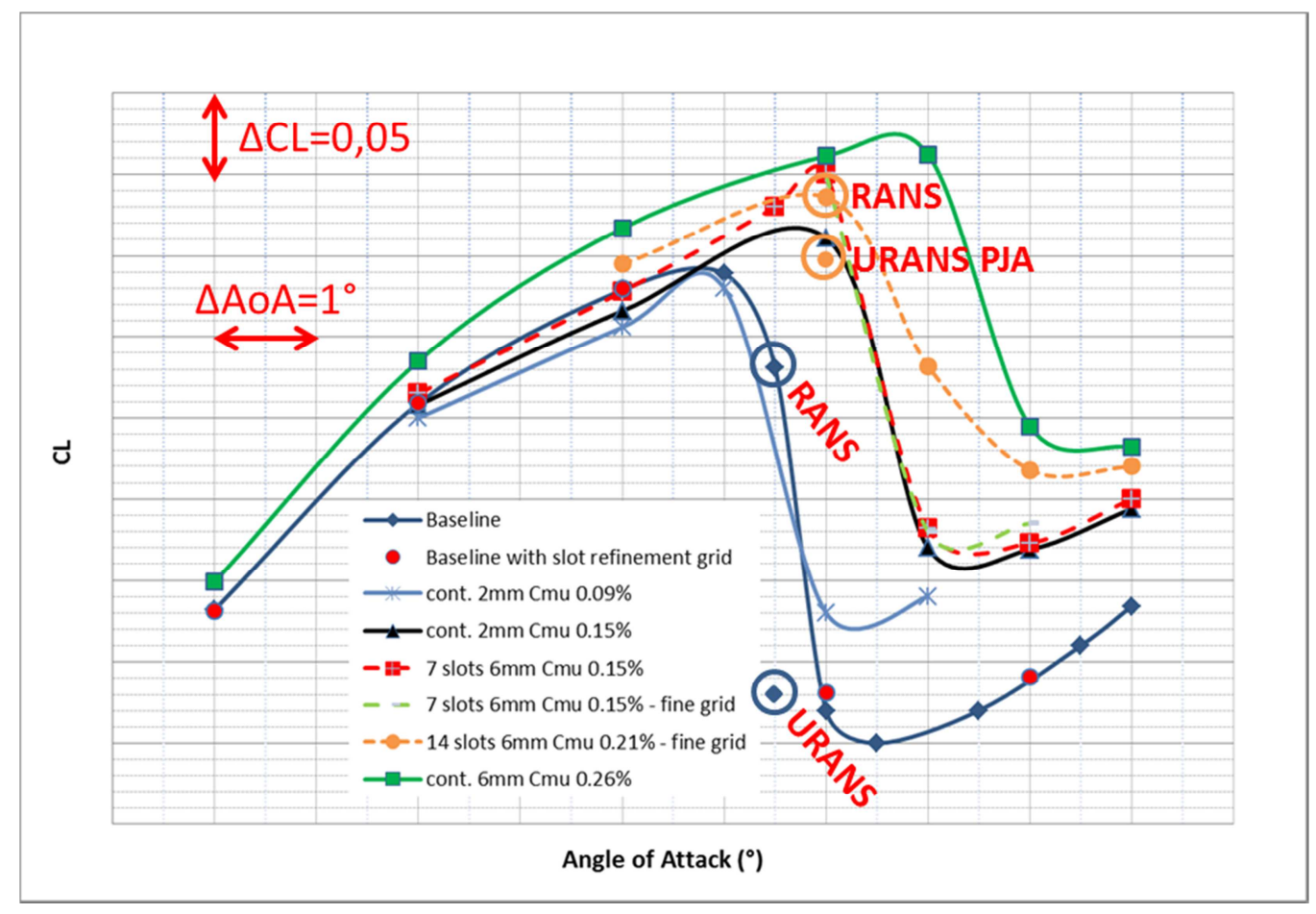

Figure 20: $C L(A o A)$; RANS and URANS AFC results; elsA.

Then, two identical systems are presented: they exhibit 7 slots $6 \mathrm{~mm}$ wide with a blowing velocity of $250 \mathrm{~m} / \mathrm{s}$, which also corresponds to a $C_{\mu}$ value of $0.15 \%$. They allow possible grid effects between the initial and refined slot grids to be investigated, as explained above. It can be observed that the red and light green lines are almost superimposed which is comforting about the initial slot grid refinement visible in Figure 15 and Figure 16. Concerning this device in itself, it can be noticed that in pre-stall conditions, it is more efficient than the continuous slot exhibiting the same $C_{\mu}$ value: a greater $C L_{\max }$ is achieved at $16^{\circ}$ and it does not provoke deterioration of the baseline polar at 12 or $14^{\circ}$. These aspects underline the potential of segmented slots. On the other hand, the poststall behavior is similar.

The 14-slot system, to be considered here in its constant blowing version (all the slots are blowing continuously), exhibits a relatively high $C_{\mu}$ value of $0.21 \%$ which allows an overall better gain than the previous devices, even if 
the $C L_{\max }$ coefficient is a bit lower. It is really interesting to observe that this system in particular seems to produce a fairly smooth stall which might be valuable for aircraft handling qualities.

Finally, the AFC device with the highest $C_{\mu}$ value evaluated $(0.26 \%)$ is a continuous $6 \mathrm{~mm}$ slot which requires a mass flow rate of more than $2.5 \mathrm{~kg} / \mathrm{s}$ which is probably too demanding in terms of bleed-air requirements. With this system, the $C L_{\max }$ is significantly increased $(+0.085)$ and stall is delayed of about $2^{\circ}$. This represents a substantial $3.5 \%$ gain in $C L_{\max }$ compared to the baseline configuration and the lift levels after stall are strongly improved.

Figure 21 is focused on the global drag coefficient. The impacts of AFC systems on drag are analyzed even if this coefficient is not as important as lift during the landing phases. To start with orders of magnitude, it can be said that both structured and unstructured (not shown here) computations of the baseline configuration produce equivalent levels: roughly between 2000 and 5000 drag counts (one drag count stands for $1.10^{-4}$ ) for an angle of attack increase from 12 to $19^{\circ}$. Concerning the baseline curve, it can be noticed that the massive flow separation development generates a clearly visible and sudden drag rise that is delayed or even smoothed with AFC systems on. However, it can also be observed that the blowing AFC devices produce a drag penalty before stall compared to the baseline (but only of a few percent which might be considered as negligible for landing approaches).

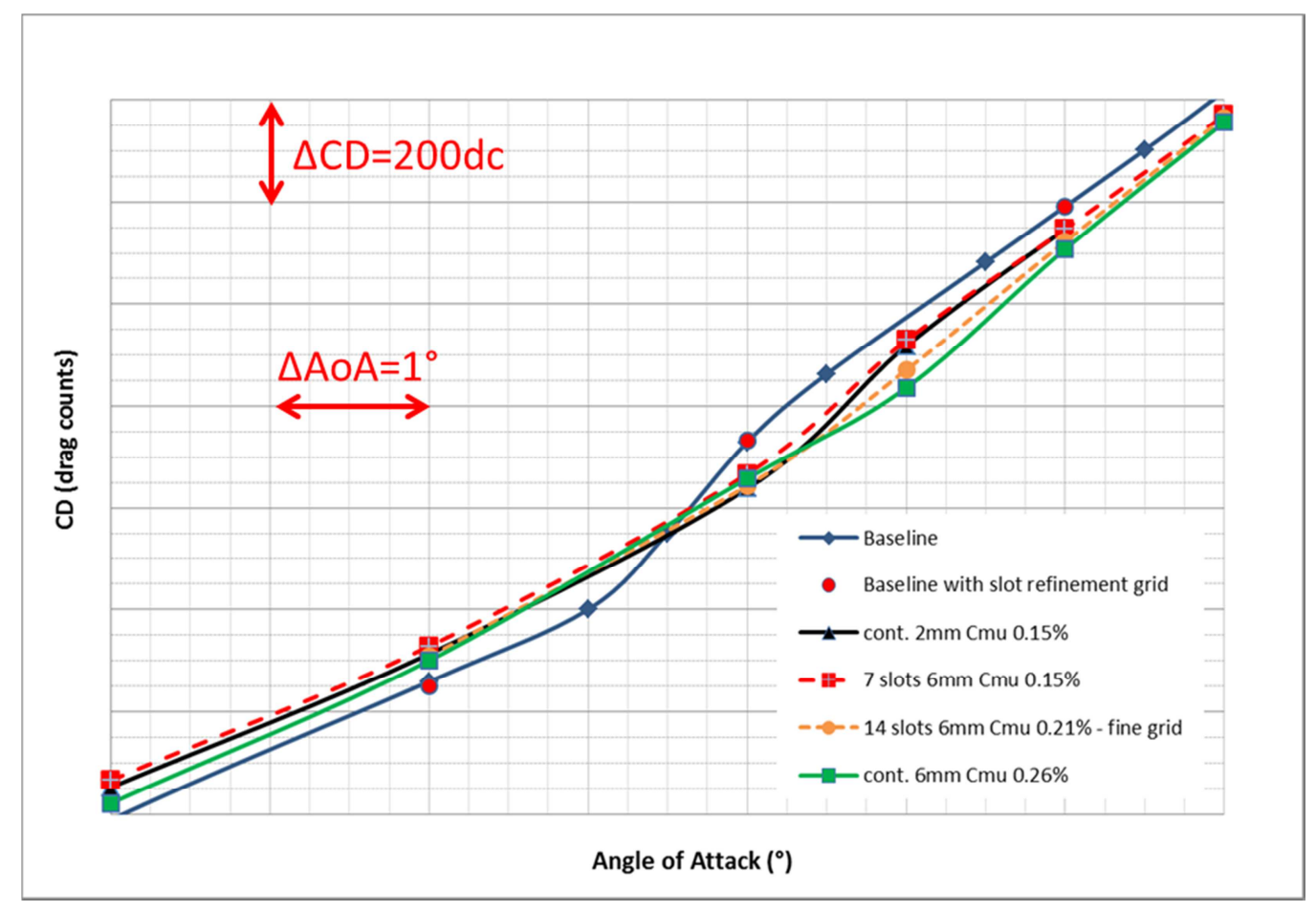

Figure 21: $C D(A o A)$; RANS AFC results; elsA.

Some local analyses will be given in the following paragraphs to explain the global coefficient evolutions. First, the skin friction coefficient and friction lines are analyzed in Figure 22. Four cases are compared at 14, 16, and 17 angles of attack corresponding to pre-stall, stall, and post-stall conditions. These four cases are the baseline configuration first and the AFC systems $n^{\circ} 2$ ( 2 mm continuous slot), $\mathrm{n}^{\circ} 4$ (6 mm 7 slots), and $\mathrm{n}^{\circ} 6$ (6 mm 14 slots) defined in Table 1. As it can be observed in Figure 22, for pre-stall conditions at $14^{\circ}$, the flow is attached for all the 
configurations (nevertheless a tiny beginning of flow separation can be seen at the wing trailing edge of the baseline). Despite the flow is attached for the four cases, even at this relatively low angle of attack, some visible differences can be noticed. Indeed, for the baseline (i.e. no flow control), some of the friction lines which start right after the pylon tend to spread over a large part of the span, announcing a zone of weak velocities and then the development of a trailing edge flow separation. On the other hand, for the configurations with flow control on, it can be observed that the more the AFC system is efficient, the more the friction lines coming from the pylon remain grouped. Then, at $16^{\circ}$, the difference for the baseline configuration is obvious: a massive flow separation has appeared. In contrast, all the cases with AFC systems active still exhibit almost fully attached flow. However, some discrepancies are noticeable between the different devices. The continuous slot and the 7-slot systems show flow features that are similar to what was observed with the baseline at $14^{\circ}$. They both have friction lines that spread downstream of the pylon and flow separations that start to appear at main wing trailing edge. Finally, at $17^{\circ}$, the four cases presented here exhibit quite massive flow separation. Nevertheless, the fact that the 14-slot device produces a relatively smooth stall can be understood here since its flow separation remains particularly limited compared to the other ones. Besides, the last line of Figure 22 allows to explain why the lift levels after stall with AFC working are much higher that the ones of the baseline configuration. Even if at a given angle of attack, the AFC systems do not prevent the flow separation development that causes the stall, they are still able to contain it.

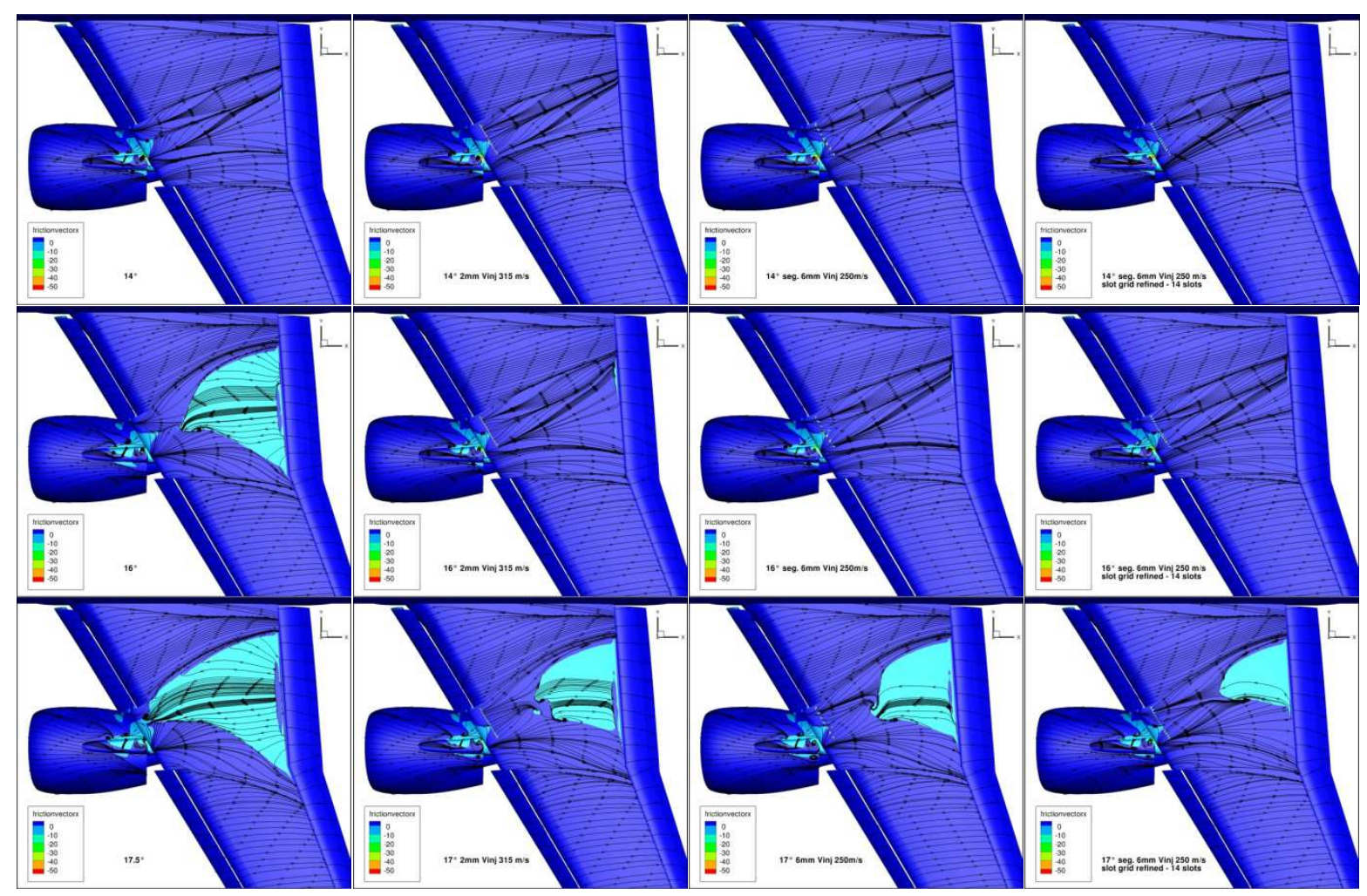

Figure 22: $C_{f x}$ distribution and friction lines at 14,16 and $17^{\circ}$ (lines) for baseline and devices $\mathrm{n}^{\circ} 2,4$, and 6 (columns). 
Still focusing on local insight, Figure 23 shows the flow patterns close to the flow control actuators. It exhibits Mach number values in the slice defined in Figure 15 as well as through iso-surfaces that describe the flow injection coming from the slots. The three devices presented are the same: $n^{\circ} 2,4$, and 6 . First, it can be observed that each AFC system, by its blowing action, re-creates the acceleration normally due to the slat/wing slot (visible here on the inboard side). Moreover, it can be noticed that the $6 \mathrm{~mm}$ slot devices ( ${ }^{\circ} 4$ and 6 ), which have greater mass flow rates, allow further propagation of the blowing velocity than $\mathrm{n}^{\circ} 2$. In all cases, this propagation is not constant over the AFC system span. It seems that the global flow (vortices coming from the inboard slat cutout and pylon in particular) participates to the injection propagation downstream of the actuators. The Mach number fields in the considered slice highlight how the injected flow spreads over the wing for each system. It is reminded that the mass flow rate per slot of the 14 -slot device $\left(n^{\circ} 6\right)$ is lower than the one of the 7 -slot device $\left(n^{\circ} 4\right)$. This explains why the injection of the third image of first line is not as strong as the one of the second image.

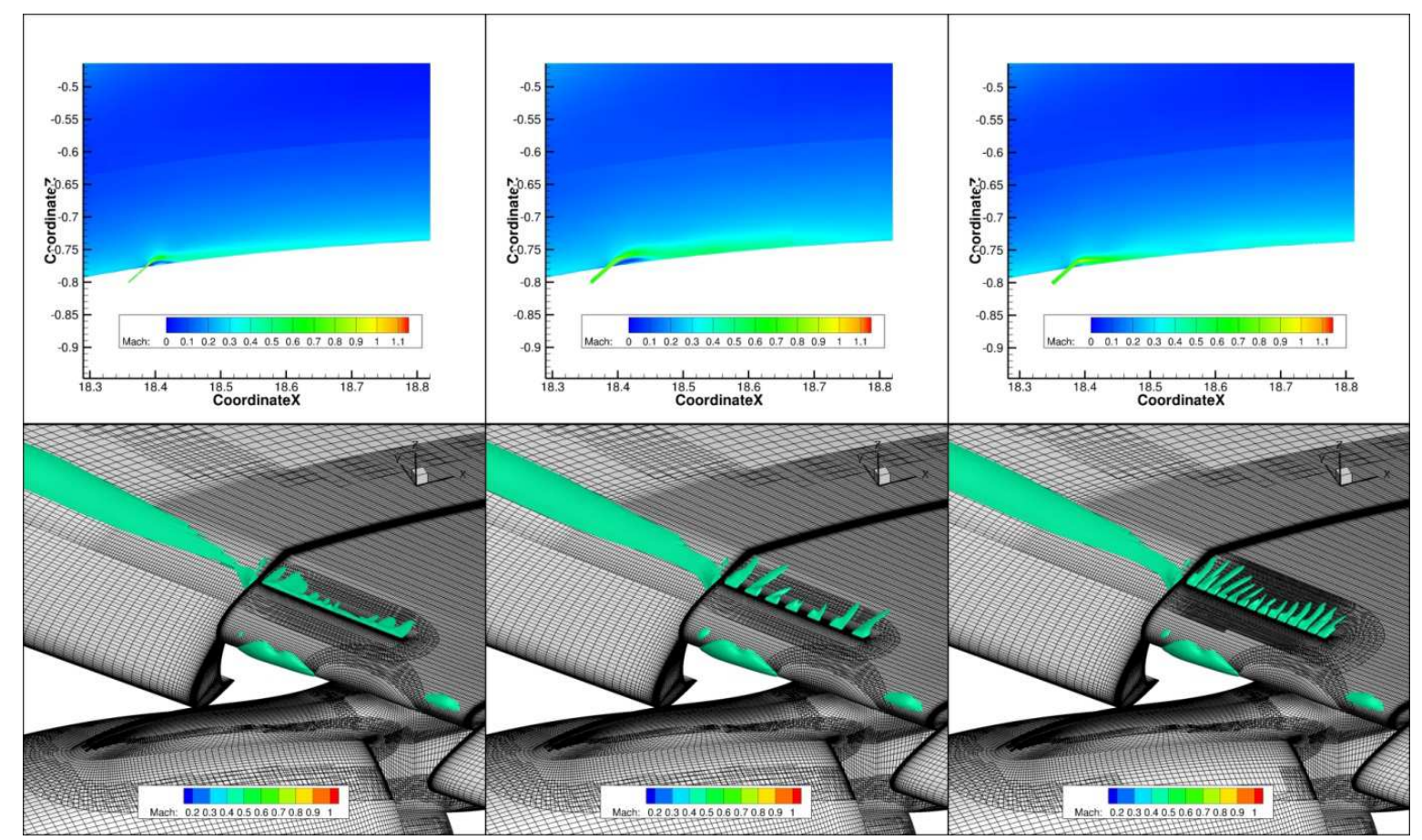

Figure 23: Slices and iso-surfaces (value=0.45) of Mach number showing the AFC injection at $16^{\circ}$ for devices $n^{\circ} 2,4$, and 6 .

The results presented in this section are consistent: as expected, the gain that can be obtained via the AFC system is directly related to the $C_{\mu}$ value which represents the force given to the fluid. In these constant blowing conditions, it seems that all the AFC systems evaluated allow significant lift level gains after stall; this is true even for devices with $C_{\mu}$ values too low to improve the $C L_{\max }$. The segmentation of the blowing slot at iso- $C_{\mu}$ seems interesting. In the end, the results show that if the $C_{\mu}$ coefficient is high enough, a constant blowing AFC system can be efficient to delay and control the massive flow separation which normally appears in the nacelle wake. The wing stall is delayed of 1 to $2^{\circ}$ of angle of attack and the $C L_{\max }$ is improved of a few percent. 


\section{URANS simulations}

The results presented in this section are from ONERA. The aerodynamic conditions are still the same. Two URANS calculations were completed: one of the baseline configuration without flow control in stall conditions and one with the 14-slot AFC system in pre-stall conditions. Only two computations were carried out because the CPU cost of such unsteady cases is extremely high. The simulations took about 60 days of calculation each (CPU time). It asked more than 6 months in real time on the ONERA HPC server. As a reminder, the grids are composed of about 70 million cells.

Figure 20 in the former section gives the average lift coefficients obtained with these two computations. They are circled and referenced as URANS. First, the baseline configuration at $15.5^{\circ}$ was studied to investigate the effects of URANS on stall prediction. Indeed, it can be observed that this angle of attack corresponds to the beginning of stall/flow separation in RANS. For the URANS computation involving an AFC system, the 14-slot device in pulsed blowing mode $\left(\mathrm{n}^{\circ} 7\right)$ was chosen. The angle of attack of $16^{\circ}$ was preferred because it might be considered as the point of main interest $\left(C L_{\max }\right)$. Both URANS calculations have been initiated with the associated RANS solutions (see Figure 20). In the case of the baseline configuration in stall conditions, it should be noticed that the RANS solution presented non-negligible oscillations of the fluxes. This was not the case for the configuration with flow control.

For the URANS computation of baseline at $15.5^{\circ}$, the following settings were applied:

- runs 1 to 50: time step of $1.67 \times 10^{-4} \mathrm{~s}$ with 200 DTS sub-iterations / iteration - 50 iterations / run,

- runs 51 to 70 : time step of $1.67 \times 10^{-4} \mathrm{~s}$ with $100 \mathrm{DTS}$ sub-iterations / iteration - 100 iterations / run (the number of DTS sub-iterations was reduced to perform more iterations during a run in order to go through the transient regime more rapidly),

- runs 71 to 100: time step of $1.67 \times 10^{-3} \mathrm{~s}$ with 100 DTS sub-iterations / iteration - 100 iterations / run (the time step was increased to go through the transient regime more rapidly, no problem of stability was encountered).

These steps led to a total physical time of 5.76 seconds. The lift and drag convergence curves of this computation can be observed in Figure 24. It can be noticed, as mentioned above, that the RANS computation (before iteration 0) shows large oscillations due to the changing flow features at this angle of attack without control (imminent substantial flow separation development). Then, it can be observed that the URANS simulation predicts a decreasing lift which has been accelerated with the time step raise to finally converge to an average value 0.22 below the RANS mean value. This decrease in $C L$ is quite significant and leads to levels that are similar to the ones obtained with an angle of attack of $16^{\circ}$ in RANS, angle at which the flow separation is already massive. This is illustrated in Figure 25 which gives the RANS and URANS skin friction and friction lines at $15.5^{\circ}$. It confirms that the URANS at $15.5^{\circ}$ is close to the RANS at $16^{\circ}$. This can indicate that stall might appear for slightly lower angles of attack than what the RANS predicted. 


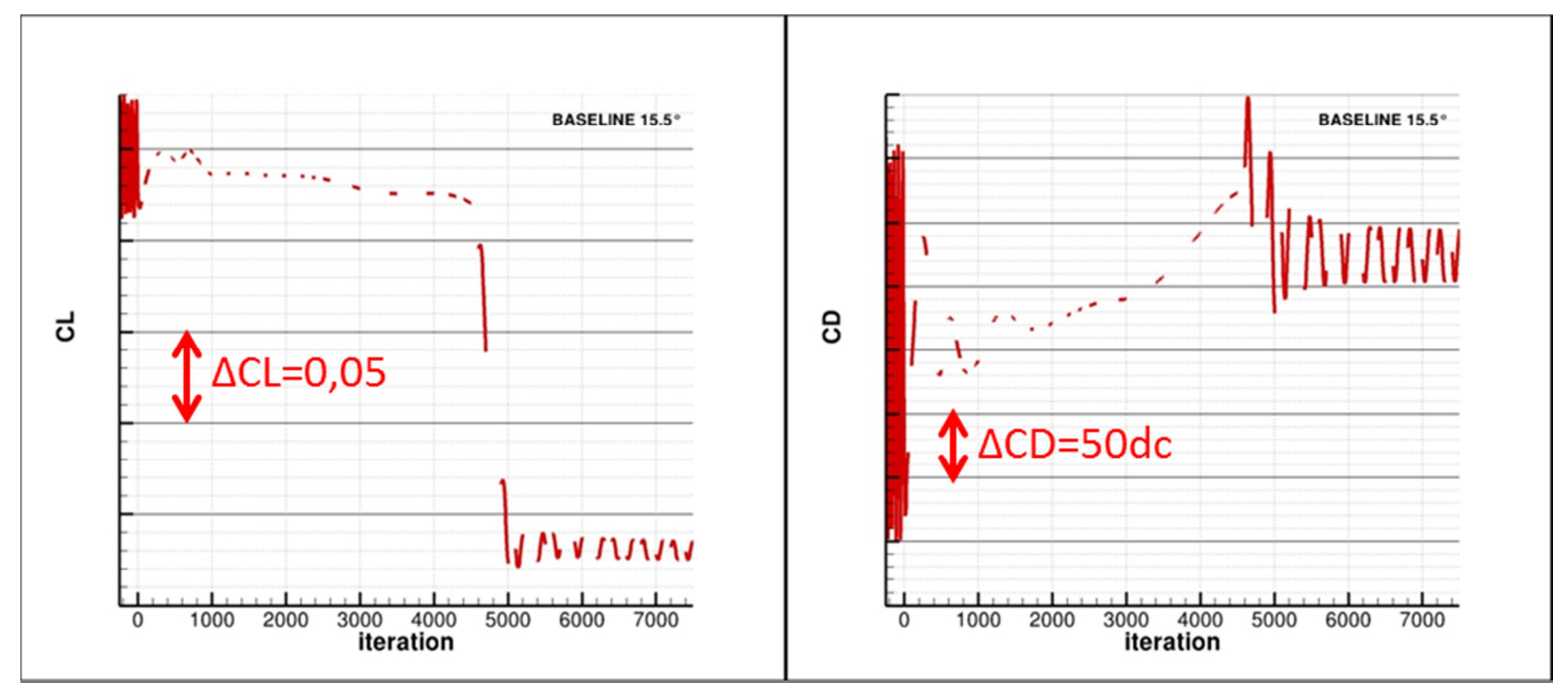

Figure 24: $C L$ and $C D$ convergence curves at $15.5^{\circ}$; URANS baseline (each dash is a $15 \mathrm{~h}$ run - not all runs extracted from server).

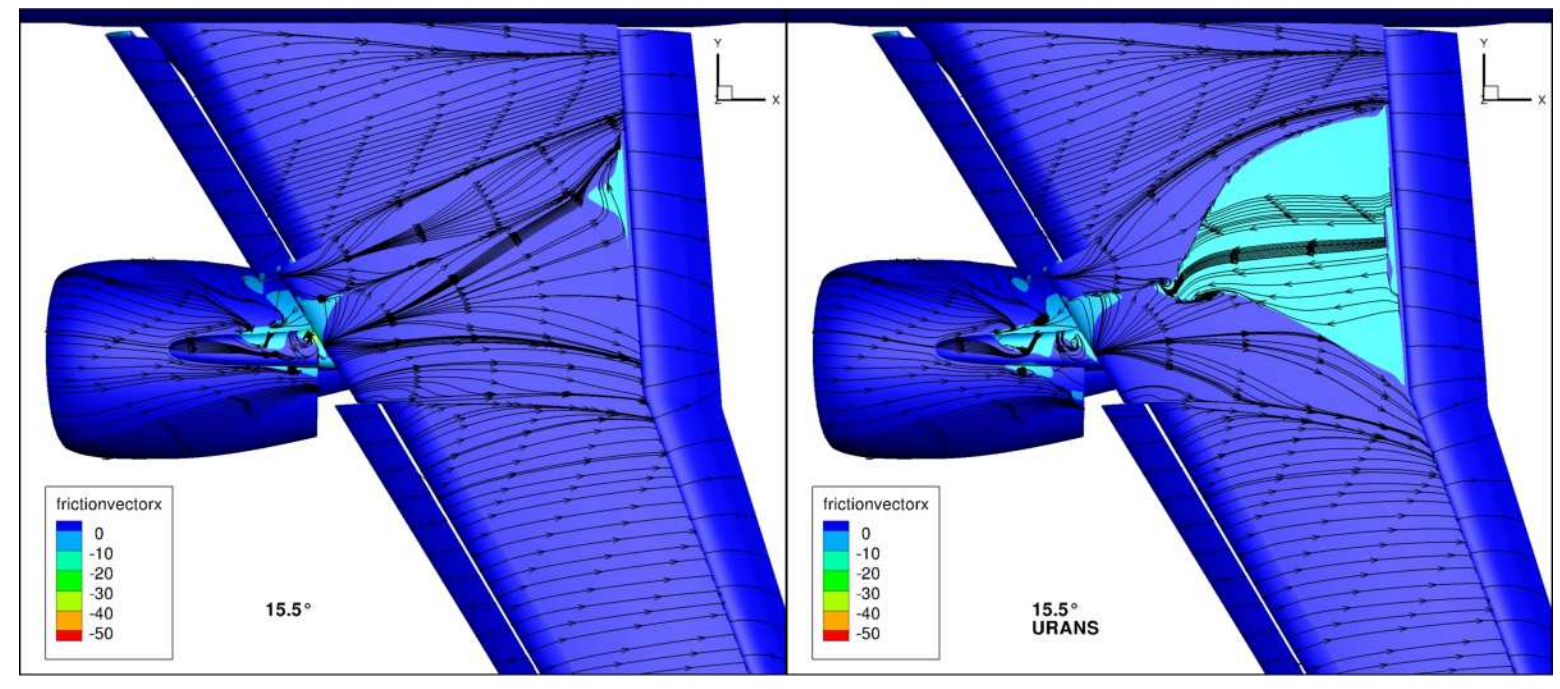

Figure 25: $C_{f x}$ distribution and friction lines at $15.5^{\circ}$; baseline RANS vs URANS.

The URANS simulation with the 14-slot device has needed 130 runs (10-15 hours each) on 256 cores. The settings have been chosen according to the blowing frequency of $60 \mathrm{~Hz}$ (rectangular signal with duty cycle of 0.5 ). A minimum of 100 time steps by signal period has been applied:

- $\quad$ runs 1 to 50: time step of $4.17 \times 10^{-5} \mathrm{~s}$ with 200 DTS sub-iterations / iteration - 100 iterations / run,

- $\quad$ runs 51 to 90: time step of $1.67 \times 10^{-4} \mathrm{~s}$ with 200 DTS sub-iterations / iteration - 100 iterations / run (the time step has been slightly increased to go through the transient regime more rapidly),

- $\quad$ runs 91 to 125 : time step of $1.67 \times 10^{-4} \mathrm{~s}$ with 100 DTS sub-iterations / iteration - 200 iterations / run (the number of DTS iterations has been reduced to perform more iterations during a run),

- $\quad$ runs 126 to 130: time step of $4.17 \times 10^{-5} \mathrm{~s}$ with 100 DTS sub-iterations / iteration - 200 iterations / run (the time step has been set to its initial value to investigate potential effects). 
These steps led to a total time of 2.05 seconds. The lift and drag convergence curves of this AFC computation are presented in Figure 26. It is important to notice that in Figure 24, for the baseline, the scale of $C L$ axis is one hundredth vs. one thousandth here (ten drag counts vs. one for $C D$ ). As a consequence, the variation between the 14slot device in constant blowing mode (RANS) and its version in pulsed blowing mode (URANS) at $16^{\circ}$ is much more limited than between RANS and URANS for the baseline at $15.5^{\circ}$. As an illustration, the $C L$ decrease that is observed here is only 0.035 . The drag is almost not impacted. This limited lift decrease can be observed in Figure 20 with the URANS orange circle. It can be noticed that the efficiency of the 14-slot device in pulsed blowing mode at $16^{\circ}$ is almost as high as the one of the device $\mathrm{n}^{\circ} 2$ (constant blowing continuous slot) which yet exhibits greater $C_{\mu}$ and mass flow rate values. This indicates that the alternate pulsed blowing mode is an interesting approach. Besides, to consider the gain obtained with this AFC system computed via URANS in a consistent way when observing Figure 20, it should be reminded that stall seem to appear earlier in URANS than in RANS for the baseline case. Then, Figure 27 gives a direct comparison at $16^{\circ}$ between devices $n^{\circ} 6$ (constant blowing in RANS) and $n^{\circ} 7$ (pulsed blowing in URANS). It can be seen that both systems allow a correct control of the flow separation. The pulsed blowing system at right exhibits flow patterns that are very similar to the ones of device $\mathrm{n}^{\circ} 2$ at $16^{\circ}$ in Figure 22 , which is consistent with the previous observations.

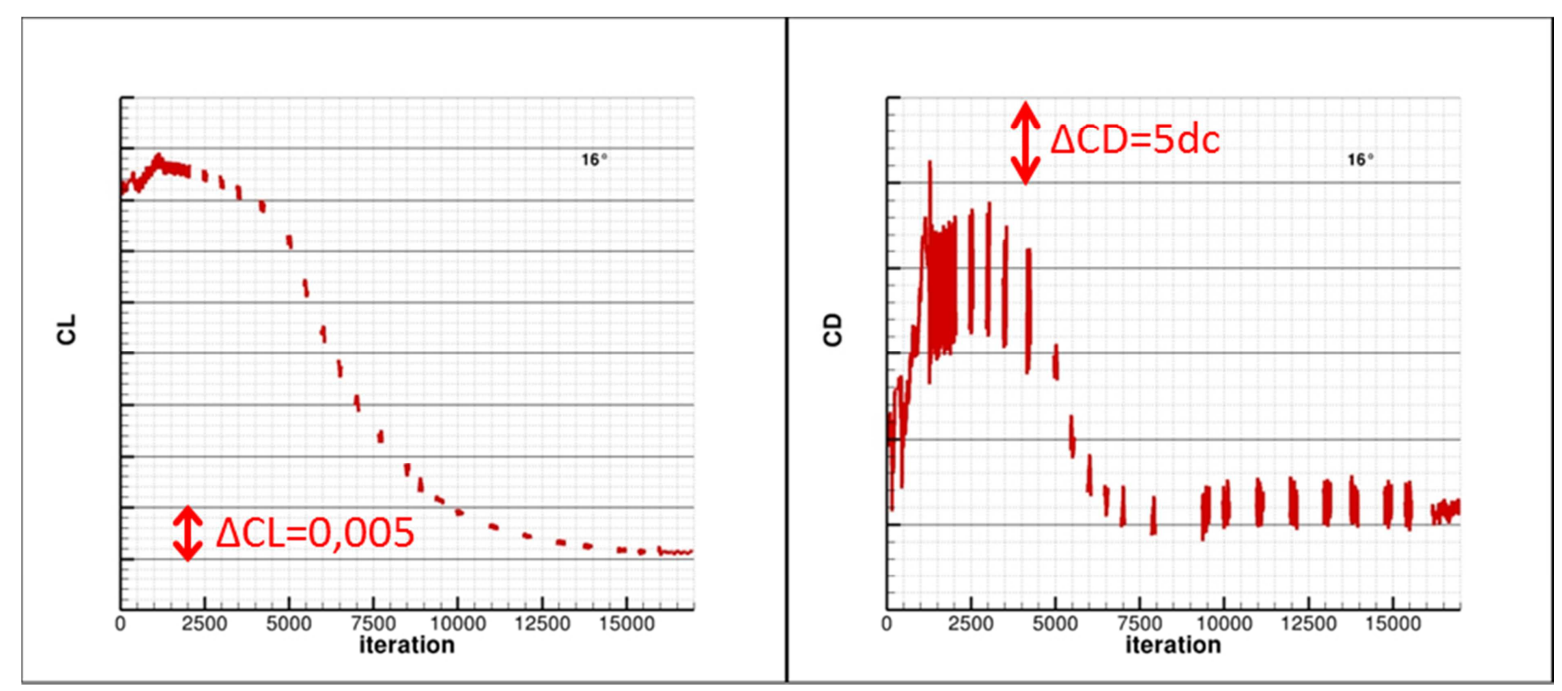

Figure 26: $C L$ and $C D$ convergence curves at $16^{\circ}$; URANS 14-slot device in pulsed blowing mode. 


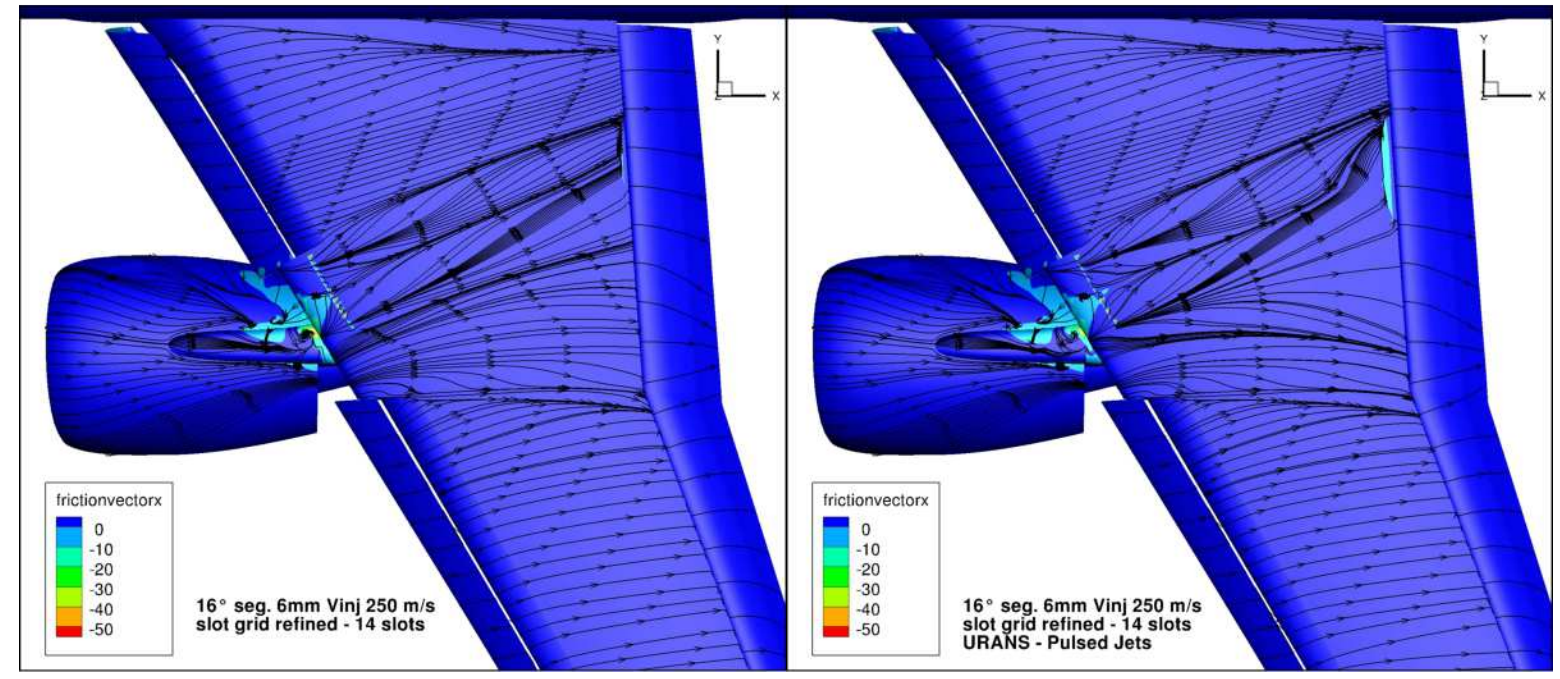

Figure 27: $C_{f x}$ distribution and friction lines at $16^{\circ}$; 14-slot device RANS (constant) vs. URANS (pulsed).

Finally, Figure 28 shows via iso-surfaces of Mach number a time at which the slots 1, 3, 5, 7, 9, 11, and 13 are blowing. The flow field around AFC actuators is very close to what was visible in Figure 23 except that in this case only one slot over two is blowing which allows the mass flow rate to be cut in half without provoking a dramatic loss in global AFC gain.

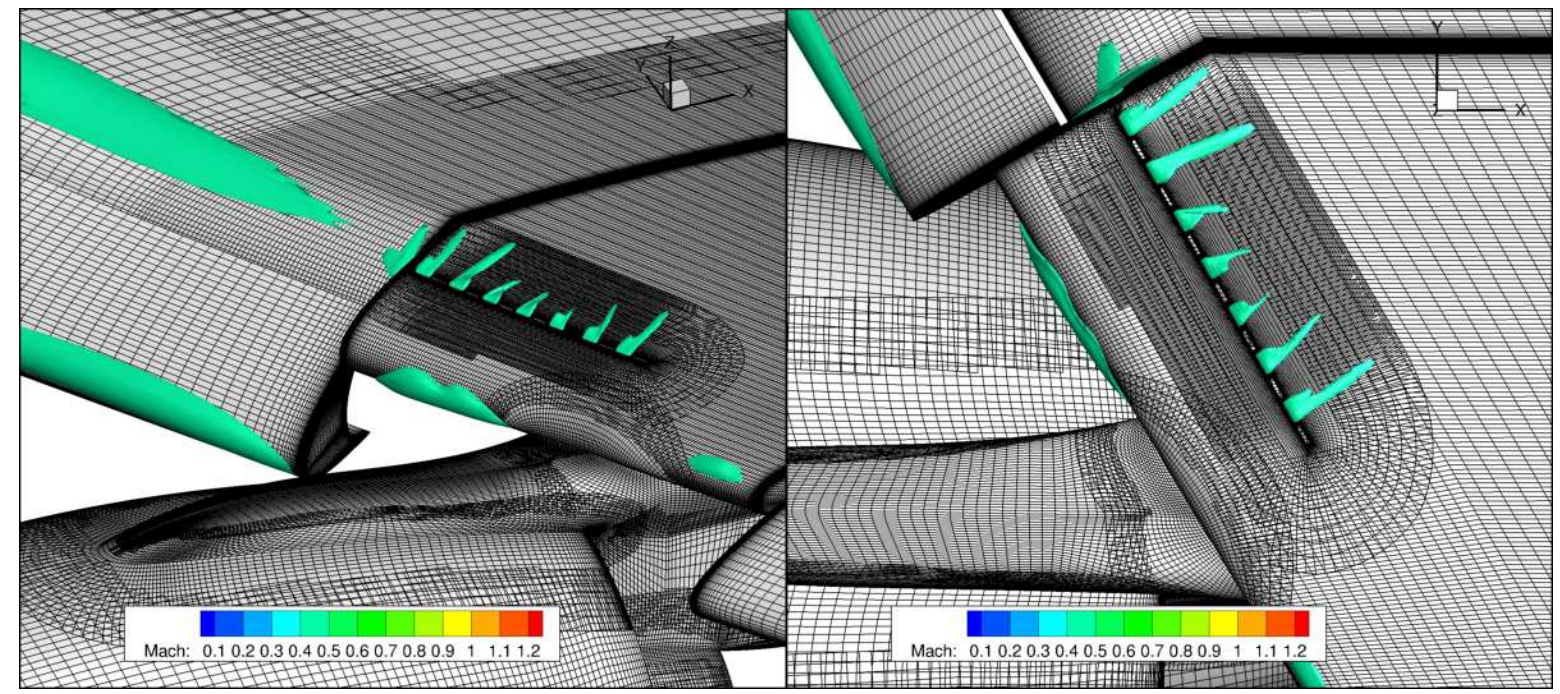

Figure 28: Iso-surfaces of Mach number (value=0.45) showing the PJA alternate injection 


\section{Conclusions}

In the framework of the $2^{\text {nd }}$ work package of the European Project AFLoNext, DLR and ONERA performed numerical studies on a realistic high-lift aircraft configuration including slats and flap deployed for landing conditions as well as a high bypass ratio engine. The purpose of these activities was to assess the potential of active flow control systems to delay and contain the nacelle wake separation that eventually appears on the wing suction side at high angles of attack.

To complete these computations, overset structured and unstructured grids were generated respectively for the ONERA and DLR Navier-Stokes solvers. For the baseline configuration without flow control, the maximum lift coefficient $C L_{\max }$ and the angle of attack at which the massive flow separation appears were determined and the flow patterns, especially the vortex system (from pylon, slats, and strake), were studied. The DLR and ONERA results on the baseline exhibit very good agreement. This cross-validation is satisfactory and gives good confidence in these CFD results.

Following this work, several AFC systems were defined and evaluated, at first with RANS computations. Different slot sizes and types (continuous vs. segmented) and/or blowing velocities were proposed. The potential of each system was shown over a whole polar in comparison with the baseline. The gain that is obtained with an AFC system is consistent with its $C_{\mu}$ coefficient value which represents the actuation force over the flow. In constant blowing mode, all the AFC systems assessed in this study produce lift level gains after stall (typically about $+5 \%$ ). It was demonstrated that for $C_{\mu}$ values compatible with aircraft manufacturer requirements, a constant blowing AFC system is efficient to delay and contain the massive flow separation which extends downstream of the engine/wing junction without control: the wing stall can be delayed of 1 to $2^{\circ}$ of angle of attack with the considered devices and settings, and also be smoothed and the $C L_{\max }$ can be slightly increased (1 to $3 \%$ ).

As a last step, URANS computations have been performed to assess the potential gain of a pulsed jet actuator. The 14-slot system, which is probably the device the most representative of what may be tested in future AFLoNext wind tunnel tests, was evaluated with each slot blowing out of phase with its neighbours. The baseline without control has also been computed as a reference point in URANS. The gain obtained with the pulsed blowing system is similar to the one of constant blowing devices that have greater $C_{\mu}$ and mass flow rate values, which seems to confirm that this type of AFC approach can be promising. 


\section{Acknowledgments}

The work described in this paper and the research leading to these results has received funding from the European Community's Seventh Framework Programme FP7/2007-2013, under grant agreement $\mathrm{n}^{\circ}$ 604013, AFLoNext project. The authors thank all their partners of the work package 2.1 as well as their work package leaders M. Meyer and J. Wild. They also thank J.L. Hantrais-Gervois (ONERA) and S. Fricke (DLR) for their contribution. DLR thanks the Aircraft Research Association for creating the unstructured grids.

\section{References}

${ }^{1}$ Rudnik, R., "Stall behaviour of the EUROLIFT high lift configurations," AIAA paper, 836, 2008.

${ }^{2}$ Geyr, H., Schade, N., van der Burg, J. W., Eliasson, P., and Esquieu, S., "CFD Prediction of Maximum Lift Effects on Realistic High-Lift-Commercial-Aircraft-Configurations within the European project EUROLIFT II,” AIAA paper, 4299, 2007.

${ }^{3 .}$ AFLoNext website: http://www.aflonext.eu/

${ }^{4}$.Fricke, S., Ciobaca, V., Kröhnert, A., Wild, J. and Blesbois, O., “Active Flow Control Applied at the Engine-Wing Junction,” 5th CEAS Air and Space Coneference, 2015.

${ }^{5}$ Fricke, S., Ciobaca, V., Wild, J. and Norman, D., "Numerical Studies of Active Flow Control Applied at the Engine-Wing Junction," In Advances in Simulation of Wing and Nacelle Stall (pp. 397-411). Springer International Publishing, 2016.

${ }^{6}$ Ternoy, F., Dandois, J., David, F. and Pruvost, M., “Overview of ONERA Actuators for active flow control,” AerospaceLab, (6), 2013.

${ }^{7}$ Greenblatt, D. and Wygnanski, I. J., "The control of flow separation by periodic excitation,” Progress in Aerospace Sciences, 36(7), 487-545, 2000.

${ }^{8}$ Sellers, W. L., Jones, G. S. and Moore, M. D., "Flow Control Research at NASA Langley in Support of High-Lift Augmentation," AIAA paper 2002-6006, 2002.

${ }^{9}$ Benoit, C., Jeanfaivre, G., Cannone, E., "Synthesis of ONERA Chimera method developed in the frame of CHANCE program," $31^{\text {st }}$ European Rotorcraft Forum, 2005.

${ }^{10}$ Hue, D. et al., "Validation of a near-body and off-body grid partitioning methodology for aircraft aerodynamic performance prediction," Computers \& Fluids, doi:10.1016/j.compfluid.2015.05.021.

${ }^{11}$ Mesh Generation Software - ICEM Hexa, http://www.ansys.com/Services/training-center/platform/introduction-to-ansysicem-cfd-Hexa

${ }^{12 .}$ Mesh Generation Software - Pointwise, http://www.pointwise.com

${ }^{13}$ Péron, S., Benoit, C., Landier, S., and Raud, P., "Cassiopée: CFD Advanced Set of Services In an Open Python EnvironmEnt," 12th Symposium on Overset Grid and Solution Technology, Atlanta, 2014.

${ }^{14 .}$ Leatham, M., Stokes, S., Shaw, J., Cooper, J., Appa, J., Blaylock, T., “Automatic Mesh generation for Rapid Response Navier-Stokes Calculations," AIAA 2000-2247, 2000.

${ }^{15 .}$ Cambier, L., Heib, S., and Plot, S., "The ONERA elsA CFD Software: Input from Research and Feedback from Industry," Mechanics and Industry, Vol. 15(3), pp. 159-174, 2013.

16. Jameson, A., Schmidt, W., and Turkel, E., "Numerical Solution of the Euler Equations by Finite Volume Methods Using Runge Kutta Time Stepping Schemes,” AIAA-81-1259, 1981. 
${ }^{17 .}$ Spalart, P. R., and Allmaras, S. R., "A One-Equation Turbulence Model for Aerodynamic Flows," AIAA Paper 92-0439, 1992.

${ }^{18 .}$ Spalart, P. R., "Strategies for Turbulence Modeling and Simulations," International Journal of Heat and Fluid Flow, Vol. 21, pp. 252-263, 2000.

${ }^{19}$ Gerhold, T., "Overview of the Hybrid RANS Code TAU," Vol. 89 of Notes on Numerical Fluid Mechanics and Multidisciplinary Design, 2005.

${ }^{20 .}$ Wada, Y., Liou, M. S., "A flux splitting scheme with high-resolution and robustness for discontinuities”, AIAA Paper $94-$ 0083, 1994. 